\title{
Processes shaping the spatial pattern and seasonality of the surface air temperature response to anthropogenic forcing
}

\author{
Fangxing Tian ${ }^{1} \cdot$ Buwen Dong ${ }^{1} \cdot J^{\prime}$ Ron Robson ${ }^{1} \cdot$ Rowan Sutton $^{1} \cdot$ Laura Wilcox $^{1}$
}

Received: 1 March 2019 / Accepted: 13 March 2020 / Published online: 24 March 2020

(c) The Author(s) 2020

\begin{abstract}
In the period 1960-2010, the land surface air temperature (SAT) warmed more rapidly over some regions relative to the global mean. Using a set of time-slice experiments, we highlight how different physical processes shape the regional pattern of SAT warming. The results indicate an essential role of anthropogenic forcing in regional SAT changes from the 1970s to 2000s, and show that both surface-atmosphere interactions and large-scale atmospheric circulation changes can shape regional responses to forcing. Single forcing experiments show that an increase in greenhouse gases can lead to regional changes in land surface warming in winter (DJF) due to snow-albedo feedbacks, and in summer (JJA) due to soil-moisture and cloud feedbacks. Changes in anthropogenic aerosol and precursor (AA) emissions induce large spatial variations in SAT, characterized by warming over western Europe, Eurasia, and Alaska. In western Europe, SAT warming is stronger in JJA than in DJF due to substantial increases in clear sky shortwave radiation over Europe, associated with decreases in local AA emissions since the 1980s. In Alaska, the amplified SAT warming in DJF is due to increased downward longwave radiation, which is related to increased water vapor and cloud cover. In this case, although the model was able to capture the regional pattern of SAT change, and the associated local processes, it did not simulate all processes and anomalies correctly. For the Alaskan warming, the model is seen to achieve the correct regional response in the context of a wider North Pacific anomaly that is not consistent with observations. This demonstrates the importance of model evaluation that goes beyond the target variable in detection and attribution studies.
\end{abstract}

\section{Introduction}

Global land surface air temperature (SAT) increased sharply during the twentieth century. This warming is spatially and temporally non-uniform (Ji et al. 2014). Ji et al. (2014) further found that detectable warming $(>0.5 \mathrm{~K})$ started over the global land before over global ocean and accelerated until around 1980 while both the warming rate and spatial structure have changed little since.

The strong warming over land has societal and economic impacts, since it is associated with the changes in the intensity and frequency of extreme climate events, such as heatwaves, droughts, and changes in precipitation (Patz et al. 2005; Christidis et al. 2011; Dai et al. 2015; Trenberth et al. 2014; Lehmann et al. 2015, Hauser et al. 2017, Chen and Dong 2018). Thus, it is crucial to understand the

Fangxing Tian

fangxing.tian@ reading.ac.uk

1 National Centre for Atmospheric Science, Department of Meteorology, University of Reading, Reading, UK mechanisms underlying the spatial pattern and seasonality of SAT warming.

Studies based on both observations and coupled general circulation models (CGCMs) consistently show that warming is greater over land than over ocean (Dong et al. 2009, Sutton et al. 2007). Seidel et al. (2008) showed that the warming over the subtropical regions is related to the changes in atmospheric circulation, such as the changes in Hadley cells. Additionally, Huang et al. (2012) indicated that the greatest warming tends to occur in arid and semiarid regions of the mid-latitudes in the Northern Hemisphere, which implies that the limited soil moisture in the arid and semi-arid regions may also have played a role in enhancing regional surface warming.

It is well known that the increase of greenhouse gases (GHG) leads to SAT warming via the greenhouse effect. Previous studies have demonstrated that increases in GHG induce non-uniform warming, with stronger warming over the land than over the ocean (Sutton et al. 2007). The drivers of the land-sea warming contrast are also linked with different changes in lapse rate over land and sea, limitation 
of water vapor transport from sea to land, local land-air feedbacks related with the hydrological cycle, and cloud cover changes over land (Rowell and Jones 2006; Joshi et al. 2008; Bayr and Dommenget 2013; Boè and Terray 2014). The nonlinear dependence of saturation specific humidity on temperature also plays a critical role in the changes in specific humidity and lapse rate (Boè and Terray 2014; Dong et al. 2017a).

In addition to the increases in GHG, the change of anthropogenic aerosol and precursor (AA) emissions is also a key factor for SAT change. Turnock et al. (2015) and Ruckstuhl et al. $(2008,2010)$ indicated that the reduction of AA emissions over Europe in recent decades has led to more solar insolation reaching the land surface due to aerosol-radiation interaction (Boucher et al. 2013) and has resulted in enhanced local SAT warming in summer. A reduction in cloud cover further enhances the SAT warming (Boé and Terray 2014; Whan et al. 2015; Twomey 1977; Boucher et al. 2013), through aerosol-cloud interaction and land-atmosphere interaction.

Since the dominant processes and related feedbacks determine the spatial distribution of SAT warming (Huang et al. 2012), we examine the large-scale pattern and seasonality of the recent rapid surface warming during the period 1960-2010. In this study, we focus on Eurasia, Alaska, and western Europe, and investigate plausible mechanisms for
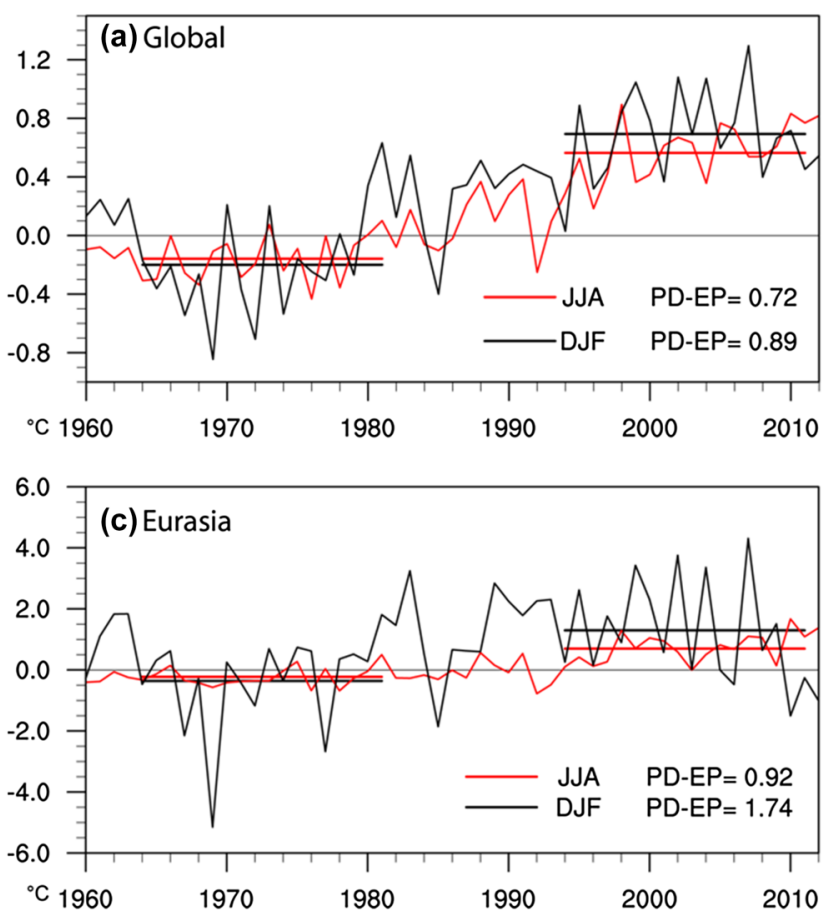

Fig. 1 Observed (CRUTS32) surface air temperature (SAT, $\left.{ }^{\circ} \mathrm{C}\right)$ variations in DJF (black) and JJA (red) averaged over a global, b western Europe $\left(10^{\circ} \mathrm{W}-30^{\circ} \mathrm{E}, 40^{\circ}-60^{\circ} \mathrm{N}\right)$, c Eurasia $\left(30^{\circ}-130^{\circ} \mathrm{E}, 40^{\circ}-60^{\circ}\right.$ $\mathrm{N})$, and d Alaska $\left(170^{\circ}-130^{\circ} \mathrm{W}, 60^{\circ}-70^{\circ} \mathrm{N}\right)$. Two horizontal bars the warming in these regions as simulated in a set of model experiments. The reasons that we focus on the three regions are clarified in Sect. 2. Note that there is no formal attribution that these mechanisms occurred in reality and the analysis simply provides plausible explanations for part of the warming. The structure of this paper is as follows. Section 2 describes the rapid SAT changes in observations; Sect. 3 describes the model and experiments; Sect. 4 elucidates the mechanisms for SAT warming over different regions in response to different forcings. The main conclusions are summarized in Sect. 5.

\section{Observed changes in surface air temperature in the period 1960-2010}

To study the observed changes in surface air temperature, we use the monthly mean Climate Research Unit (CRU) TS3.21 data set on a $0.5^{\circ} \times 0.5^{\circ}$ grid (Harris et al. 2014). Fig. 1 illustrates the time series of global, western Europe $\left(10^{\circ} \mathrm{W}-30^{\circ} \mathrm{E}, 40^{\circ}-60^{\circ} \mathrm{N}\right.$, land only), Eurasia $\left(30^{\circ}-130^{\circ} \mathrm{E}\right.$, $40^{\circ}-60^{\circ} \mathrm{N}$, land only), and Alaska $\left(170^{\circ}-130^{\circ} \mathrm{W}, 60^{\circ}-70^{\circ}\right.$ $\mathrm{N}$, land only) area averaged SAT in June-August (JJA) and December-February (DJF). For the global mean SAT, one of the most striking features is the abrupt warming in late twentieth century (Fig. 1a) with a warming magnitude of
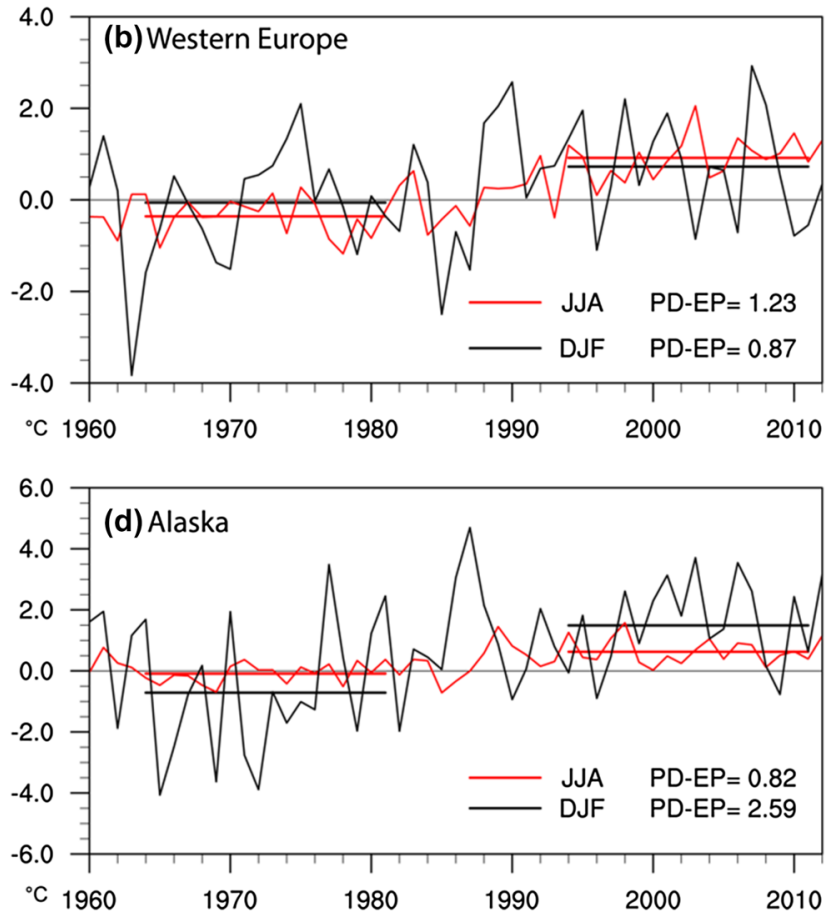

indicate the early period (EP) of 1964-1981 and the present day (PD) of 1994-2011. Numbers after PD-EP= give the magnitude of SAT changes in ${ }^{\circ} \mathrm{C}$ 
$0.72{ }^{\circ} \mathrm{C}$ in JJA and $0.89^{\circ} \mathrm{C}$ in DJF between "present day" (PD, 1994-2011) and the "early period" (EP, 1964-1981). The area averaged SAT changes between two periods shows significant seasonality in most regions (Fig. 1).

The spatial patterns of changes in SAT between PD and EP are illustrated in Fig. 2. For all maps we have done statistical significance tests on changes at a grid point level by treating each year in observations and model simulations as an independent sample to estimate noise without accounting for lag-1 errors. Note the significance test does not fully account for multidecadal variability which might mean that some of the tests are over-confident. However, here we simply aim to demonstrate that the land surface warming is not uniform in observations and model simulations in response to external forcing.

Three of the regions with strongest warming are Eurasia and Alaska in DJF, and western Europe in JJA (Fig. 2a, c). We focus on these regions as (1) they warm faster than their surroundings in both models and observations, (2) their SAT mean states are well represented in the model and (3) the seasonality of their SAT changes are represented in the model. Over Eurasia and Alaska the warming is stronger in DJF than in JJA, while the warming over western Europe is stronger in JJA than in DJF. The rapid regional warming and its seasonality can also be seen from the time evolutions of area averaged temperature anomalies. As shown in Fig. $1 \mathrm{~b}-\mathrm{d}$, Eurasia warmed by $0.92{ }^{\circ} \mathrm{C}$ in JJA and $1.74{ }^{\circ} \mathrm{C}$ in DJF between 1964-1981 and 1994-2011. Alaska warmed
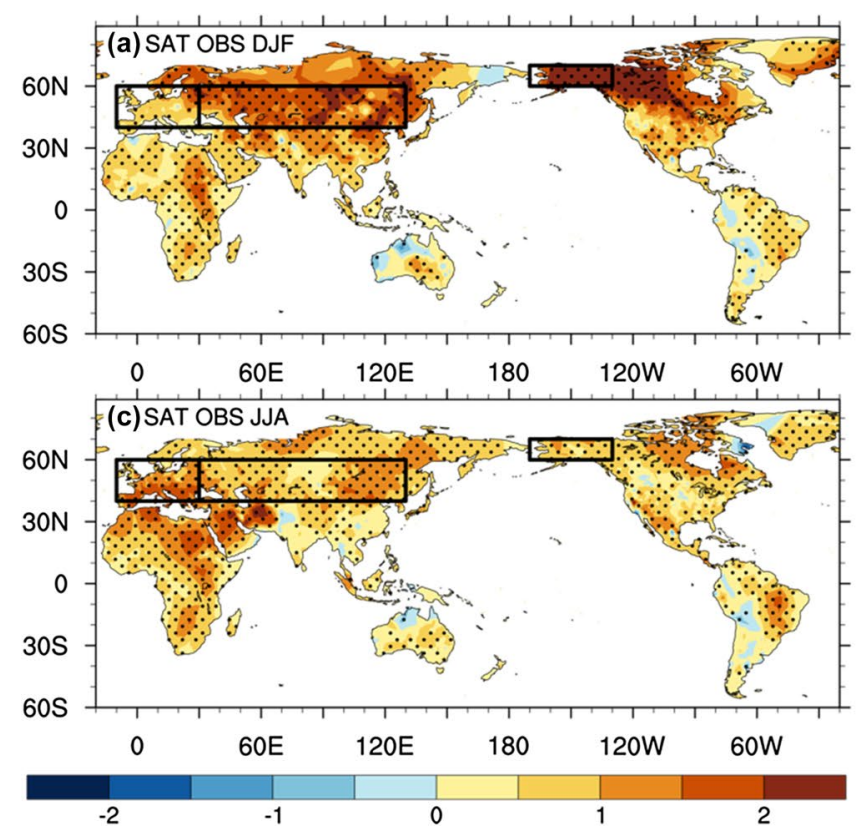

Fig. 2 Changes in SAT $\left({ }^{\circ} \mathrm{C}\right)$ in observations between PD (19942011) and EP (1964-1981) (left) and model simulated changes in response to All-forcing (right) in DJF (a, b) and JJA (c, d). Black boxes indicate the selected regions of western Europe $\left(10^{\circ} \mathrm{W}-30^{\circ}\right.$ by $0.82{ }^{\circ} \mathrm{C}$ in JJA and $2.59{ }^{\circ} \mathrm{C}$ in DJF, and western Europe warmed by $1.23{ }^{\circ} \mathrm{C}$ in JJA and $0.87{ }^{\circ} \mathrm{C}$ in DJF. All these regional SAT changes are greater than the corresponding global mean changes, indicating regionally amplified surface warming during the period 1960-2010. It is, therefore, worth understanding physical processes leading to the seasonality and local amplification of land surface warming over the three regions.

To understand the causes of this rapid warming, and the seasonality of the SAT changes in the three selected regions in observations, we performed a set of numerical experiments using a near-globally-coupled atmosphere-oceanmixed-layer model, MetUM-GOML1 (Hirons et al. 2015), with different forcings.

\section{Model and experiments}

\subsection{Model}

This work uses a near-globally-coupled atmosphere-oceanmixed-layer model (MetUM-GOML1, Hirons et al. 2015). The atmospheric component of this model is the Met Office Unified Model (MetUM) at the fixed scientific configuration Global Atmosphere 3.0 (GA3.0; Arribas et al. 2011; Walters et al. 2011). In the current study, the resolution is $1.875^{\circ}$ longitude and $1.25^{\circ}$ latitude (N96) with 85 vertical layers and the model top at $85 \mathrm{~km}$. The aerosol scheme included in
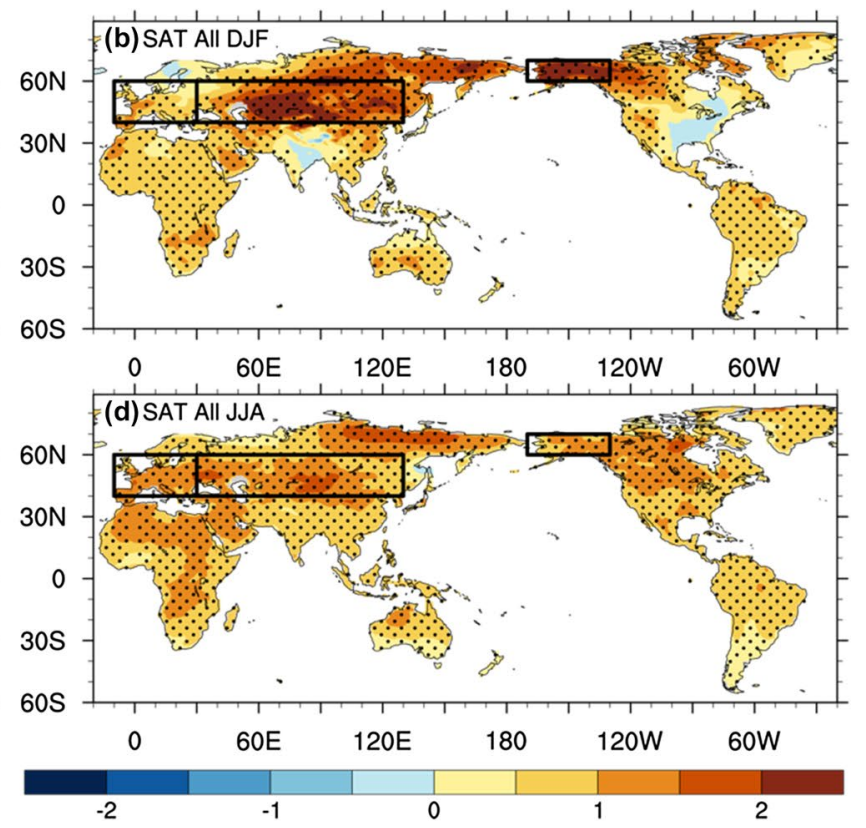

E, $\left.40^{\circ}-60^{\circ} \mathrm{N}\right)$, Eurasia $\left(30^{\circ}-130^{\circ} \mathrm{E}, 40^{\circ}-60^{\circ} \mathrm{N}\right)$, and Alaska $\left(170^{\circ}-\right.$ $\left.130^{\circ} \mathrm{W}, 60^{\circ}-70^{\circ} \mathrm{N}\right)$. Dots highlight regions where the changes are statistically significant at the $10 \%$ level using a two-tailed Student's $t$ test 
the model is the Coupled large-scale Aerosol Simulator for Studies in Climate (CLASSIC), an interactive tropospheric aerosol scheme, which can simulate the direct effect, indirect effect, and semi-direct effect of aerosols (Bellouin et al. 2007; Walters et al. 2011; Jones et al. 2011).

For the oceanic component, GOML1 employs the MultiColumn K Profile Parameterization (MC-KPP) mixed-layer ocean model. MC-KPP has the same horizontal resolution as the MetUM because it is run as a two-dimensional matrix of 1-D water columns, with one column below each AGCM grid point that is wholly or partially ocean. This study configures MC-KPP with a depth of $1000 \mathrm{~m}$ over 100 vertical levels. The vertical discretization of the MC-KPP columns is defined using a stretch function, allowing very high resolution in the upper ocean. The oceanic and atmospheric components are coupled via the Ocean Atmosphere Sea Ice Soil (OASIS) (Valcke et al. 2003) coupler. The domain of air-sea coupling is limited by the maximum extent of a seasonally varying sea ice climatology (Hirons et al. 2015). Since MCKPP simulates only vertical mixing and does not include ocean dynamics, climatological seasonal cycles of depthvarying temperature and salinity adjustments are prescribed to represent the mean ocean advection and account for biases in atmospheric surface fluxes. More details of this model and experimental design can be found in Hirons et al. (2015) and Tian et al. (2018).

\subsection{Experiments}

We summarize the experiments used in this study in Table 1. First, we performed a 12-year MetUM-GOML1 relaxation experiment in which the MC-KPP profiles of temperature and salinity were relaxed to a present day (PD; 1994-2011) ocean temperature and salinity climatology derived from the Met Office ocean analysis (Smith and Murphy 2007) in the near-globally coupled region with a relaxation time scale of 15 days.

The daily mean seasonal cycles of ocean temperature and salinity adjustments from the coupled relaxation experiment were diagnosed from the last 10 years of this simulation. These adjustments were then imposed in other four freerunning coupled model experiments. The four experiments represent the early period (1964-1981; EP), All Forcing present-day (1994-2011; PDGA), GHG forcing (PDG) and AA forcing (PDA) with the same sea ice extent as in the relaxation experiment. Therefore, the response to different forcings excludes feedbacks related to SIE changes. We ran all the experiments for 50 years and used the last 45 years of each experiment for analysis.

The forcing of the early-period (1964-1981; EP) experiment is the climatological GHG and AA forcings averaged over EP. The forcing of the all forcing present-day (1994-2011; PDGA) experiment is the climatological GHG and AA forcings in the present day. Therefore, the difference between PDGA and EP experiment (PDGA - EP) indicates the combined effect of changes in both GHG and AA (hereafter All Forcing). The forcing of the PD GHG forcing (PDG) experiment is present-day GHG but early-period AA. Therefore, the difference between PDG and EP (PDG - EP) indicates the impact of the change in GHG (hereafter GHG forcing). The forcing of the PD AA forcing (PDA) experiment is present-day AA but early-period GHG. Therefore, the impact of the change in AA emission (hereafter AA forcing) is the difference between PDA and EP (PDA - EP).

We use a Student's $t$ test to indicate the significance of mapped changes at the grid point level. Each year in a model simulation is treated as an independent sample to estimate the noise without accounting for lag-1 errors. To assess the significance of the changes in regional-mean SAT the bootstrap procedure developed by Efron and Tibshirani (1994) is conducted. This bootstrap method re-samples the

Table 1 Summary of numerical experiments

\begin{tabular}{|c|c|c|c|}
\hline Experiment & Ocean & Radiative forcing & Abv \\
\hline Relaxation run & $\begin{array}{l}\text { Relax to PD mean 3D ocean temperature and salinity } \\
\text { to diagnose climatological temperature and salinity } \\
\text { flux corrections }\end{array}$ & $\begin{array}{l}\text { Climatological PD greenhouse gases (GHG) and PD } \\
\text { anthropogenic aerosol (AA) precursor emissions } \\
\text { with GHG and AA after } 2006 \text { from RCP4.5 sce- } \\
\text { nario (Lamarque et al. 2010, 2011) }\end{array}$ & R0 \\
\hline Coupled EP experiment & $\begin{array}{l}\text { Climatological temperature and salinity flux correc- } \\
\text { tions from relaxation run }\end{array}$ & $\begin{array}{l}\text { Climatological EP GHG and EP AA precursor emis- } \\
\text { sions }\end{array}$ & EP \\
\hline \multirow[t]{3}{*}{ Coupled PD experiment } & \multirow[t]{3}{*}{$\begin{array}{l}\text { Climatological temperature and salinity flux correc- } \\
\text { tions from relaxation run }\end{array}$} & $\begin{array}{l}\text { Climatological PD GHG and PD AA precursor emis- } \\
\text { sions }\end{array}$ & PDGA \\
\hline & & $\begin{array}{l}\text { Climatological PD GHG and EP AA precursor emis- } \\
\text { sions }\end{array}$ & PDG \\
\hline & & $\begin{array}{l}\text { Climatological EP GHG and PD AA precursor emis- } \\
\text { sions }\end{array}$ & PDA \\
\hline
\end{tabular}

Early period (EP) indicates the period of 1964-1981 and present day (PD) indicates the period of 1994-2011. Note that a slightly different period of 1970-1981 for the aerosol forcing in the early period is used since aerosol emissions data before 1970 were not available 
population for 1000 times. One standard deviation of the bootstrapped samples is then used to estimate the confidence interval, which is indicated on all figures showing regional mean anomalies. Although the statistical significance tests used here are indicative of the size of the changes relative to noise, the consistency of the physical mechanisms is more important for indicating the drivers of the temperature changes and is the focus of this work.

\subsection{Model climatology}

The simulated SSTs in PD are compared with observations by Dong et al. (2017b), who showed that the biases of

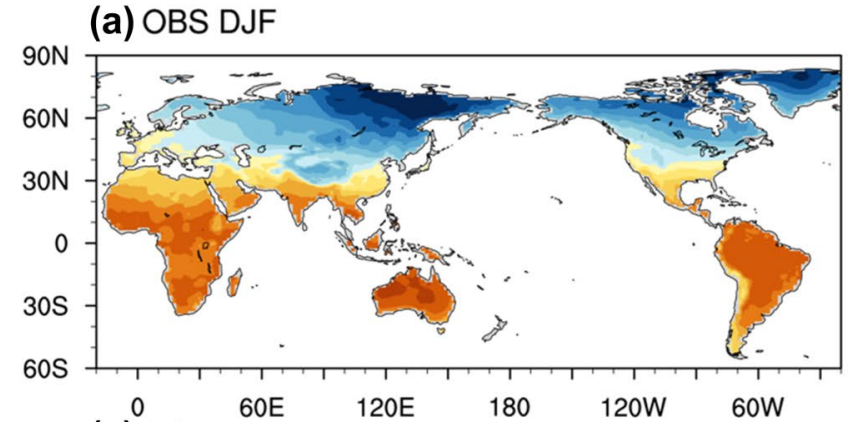

(c) GOML1 DJF
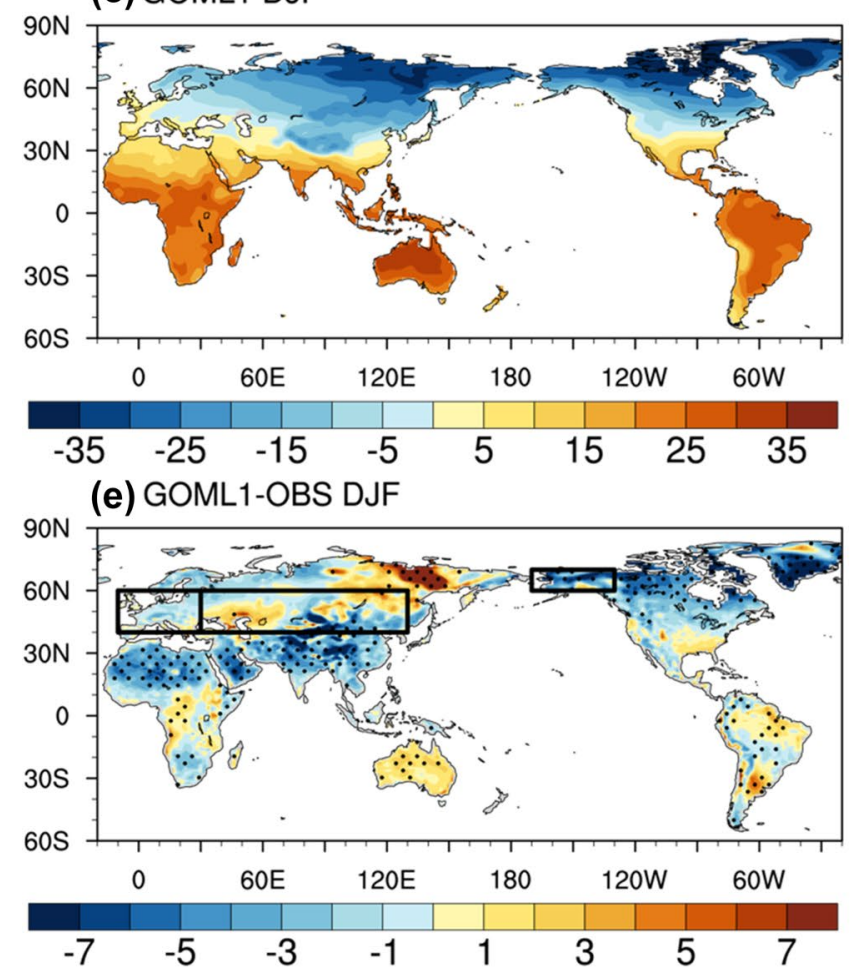

Fig. 3 Climatological SAT $\left({ }^{\circ} \mathrm{C}\right)$ in a, b observations in PD (19942011), c, $\mathbf{d}$ PD simulation and $\mathbf{e}, \mathbf{f}$ difference between simulation and observations in DJF (left) and JJA (right). Black boxes indicate the selected regions of western Europe $\left(10^{\circ} \mathrm{W}-30^{\circ} \mathrm{E}, 40^{\circ}-60^{\circ} \mathrm{N}\right)$, Eura-

simulated present-day SSTs in MetUM-GOML1 are much smaller (typically between -0.5 and $0.5^{\circ} \mathrm{C}$ ) than those in 5th Coupled Model Intercomparison Project (CMIP5) models due to the use of a flux adjustment.

Figure 3 shows the comparison between the mean SAT for the PD experiment and observations (CRU TS3.21). The significance tests may be over-confident as we do not fully take account multidecadal variability. The comparison shows that the observed spatial patterns of climatological SAT are well simulated in the model for both DJF and JJA seasons. The model has significant cold biases around North Africa in both DJF and JJA. Therefore, we do not select this region for further analysis in this study, although the observed trends are large in JJA. Additionally, due to the

(b) OBS JJA

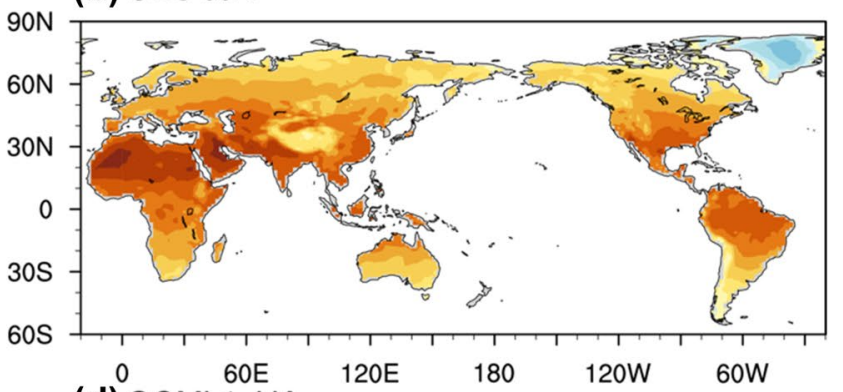

(d) GOML1 JJA
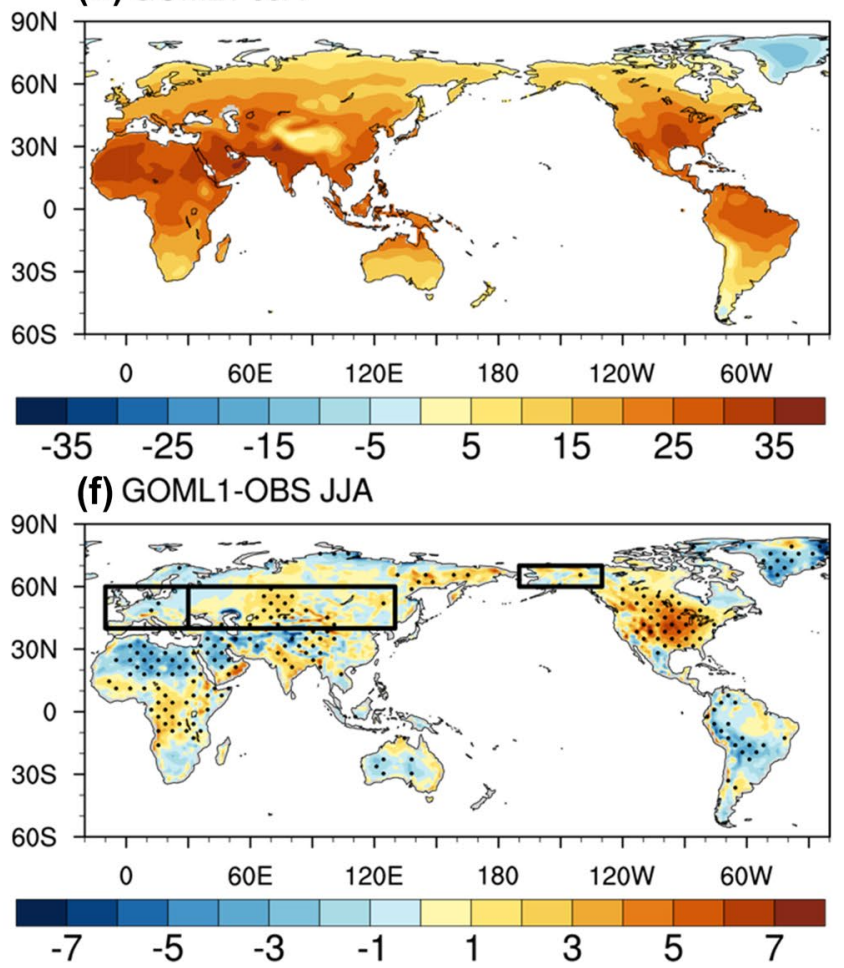

sia $\left(30^{\circ}-130^{\circ} \mathrm{E}, 40^{\circ}-60^{\circ} \mathrm{N}\right)$, and Alaska $\left(170^{\circ}-130^{\circ} \mathrm{W}, 60^{\circ}-70^{\circ} \mathrm{N}\right)$. Dots in $\mathbf{e}$ and $\mathbf{f}$ highlight regions where the differences are statistically significant at the $10 \%$ level using a two-tailed Student's $t$ test 
cold bias in the Iranian Plateau in DJF and warm bias in North America in JJA (Fig. 3e, f), these two regions are not selected for further analysis in this work. In general, the biases over most regions are relatively small in comparison with the CMIP5 models. The model has cold bias with the maximum of $5{ }^{\circ} \mathrm{C}$ over western Asia $\left(60^{\circ}-90^{\circ} \mathrm{E}\right)$, which is similar to the bias in the multi-model mean of 20 CMIP5 models (Chen and Frauenfeld 2014). Another region with a cold bias is Alaska in DJF. The maximum value in our model is about $4{ }^{\circ} \mathrm{C}$, which is larger than multi-model mean bias in CMIP5 models of around $2{ }^{\circ} \mathrm{C}$ (Knutson et al. 2013). However, the bias is not outside the spread of models, which means it is not a badly biased model.

\section{Understanding regional surface air temperature changes}

In observations based on the Berkeley Earth Surface Temperature dataset (BEST) (Rohde et al. 2013), the global mean SAT warming is $0.48{ }^{\circ} \mathrm{C}$ in DJF and $0.47^{\circ} \mathrm{C}$ in JJA (PD - EP), while in response to changes in All forcing they are $0.55{ }^{\circ} \mathrm{C}$ in DJF and $0.56{ }^{\circ} \mathrm{C}$ in JJA. The model simulated warming in the two seasons is larger by $13 \%$ or $16 \%$ than observed changes. One factor responsible for the large warming is that the model simulates committed warming (e.g., Mauritsen and Pincus 2017). The spatial patterns of simulated SAT changes in response to All-forcing are illustrated in Fig. 2b, d. The simulated changes show large warming over Eurasia, Alaska, and western Europe in both seasons. The largest warming occurs in DJF over most parts of the mid and high latitudes in the Northern Hemisphere, except over western Europe where larger warming occurs in summer. Both the spatial pattern and seasonality of the simulated SAT warming are close to those seen in observations (Fig. 2a, c) with a pattern correlation of 0.81 in DJF and 0.88 in JJA. To test the robustness of the similarity of the warming patterns between observations and model simulated changes, we normalized the SAT changes in observations and model simulations by the corresponding global mean of surface warming in both DJF and JJA (not shown). The patterns and seasonality of the warming are similar between observations and model simulations, indicating different global mean warming in observations and model simulated warming has a weak impact on the spatial patterns of SAT changes. The similarity between SAT changes in simulations and observations suggests that the observed SAT warming and its seasonal variation in various regions are likely to be a response to anthropogenic forcing.

Since the model can explain the pattern of the observed changes in SAT over the period 1960-2010, the next issue is to determine the relative contributions from changes in GHG and AA emissions. As shown in Fig. 4, the SAT warming in large land areas in both seasons is predominately due to the increase in GHG forcing. In the Northern Hemisphere,
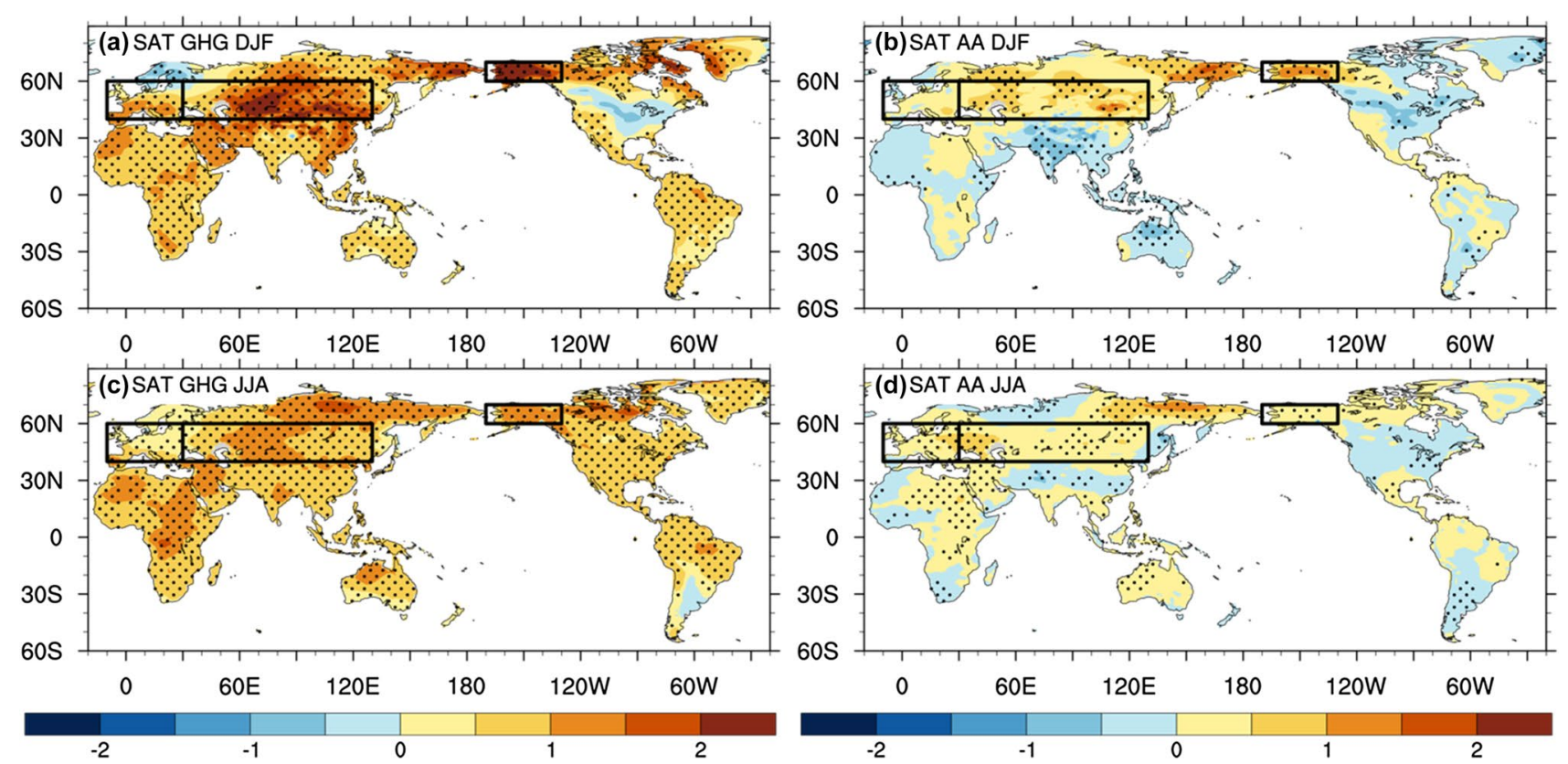

Fig. 4 Spatial pattern of surface air temperature changes $\left(\mathrm{SAT},{ }^{\circ} \mathrm{C}\right)$ in response to GHG forcing (left) and AA forcing (right) in DJF (top) and JJA (bottom). Black boxes indicate the selected regions of western Europe $\left(10^{\circ} \mathrm{W}-30^{\circ} \mathrm{E}, 40^{\circ}-60^{\circ} \mathrm{N}\right)$, Eurasia $\left(30^{\circ}-130^{\circ} \mathrm{E}, 40^{\circ}-60^{\circ}\right.$

$\mathrm{N})$, and Alaska $\left(170^{\circ}-130^{\circ} \mathrm{W}, 60^{\circ}-70^{\circ} \mathrm{N}\right)$. Dots highlight regions where the changes are statistically significant at the $10 \%$ level using a two-tailed Student's $t$ test 
the GHG induced warming is stronger in DJF (Fig. 4a) than in JJA (Fig. 4c), except for local cooling over Scandinavia and North America in DJF, which result from changes in circulation (not shown).

The changes in AA emissions induce warming over western Europe, Eurasia, and Alaska with some seasonal variations, but with weaker magnitudes in comparison with those changes induced by GHG forcing (Fig. 4b, d). The warming is relatively strong in DJF over Eurasia and Alaska and is strong and significant in the regional mean in both seasons over western Europe (Fig. 5).

In summary, changes in SAT in response to GHG and AA forcings show large spatial and seasonal variations. The spatial and seasonal variations intimate an essential role for changes in regional circulation and local land surface feedbacks in the simulated responses in SAT. Since the greenhouse gas effect is well understood by many previous studies (Lashof and Ahuja 1990; Rodhe 1990; Feldman et al. 2015), in the following section, we focus on the local feedbacks that amplify the greenhouse effect and elucidate the physical processes involved in different regions by focusing on changes in surface energy components and related feedbacks over land. Note that the rest of Sect. 4 is about physical processes inferred from the model results only and makes no causal statements about observed changes.

\subsection{Western Europe}

The regional mean SAT warming over western Europe $\left(10^{\circ}\right.$ $\mathrm{W}-30^{\circ} \mathrm{E} 40^{\circ}-60^{\circ} \mathrm{N}$, land only) is illustrated in Fig. 5a. In observations, the SAT increases by $0.87^{\circ} \mathrm{C}$ in DJF and 1.23 ${ }^{\circ} \mathrm{C}$ in JJA from the period of $1964-1981$ to the period of 1994-2011. The magnitude of observed warming is generally well captured in the All-forcing experiment, although the simulated SAT warming is slightly weaker than in observations in DJF. The experiments with individual forcings indicate that the warming over western Europe in DJF is predominantly due to the response to GHG forcing while AA forcing contribute more to surface warming in JJA. Note that due to the non-linearity and noise in the combined effect from different forcings, the sum of the warming resulting from GHG and AA forcing is not necessarily equal to the warming in All-forcing experiment.

In both observations and the All-forcing experiment, the warming in western Europe is stronger in JJA than in DJF (Fig. 2). As addressed in Seneviratne et al. (2006), the increasing in GHG concentrations enhances land surface warming in Europe in summer via land-atmosphere interaction. However, in our model simulations (Fig. 5a), this seasonality is dominated by the AA forcing. To understand the seasonality, the spatial patterns of changes in summer mean SAT and related variables induced in the AA-forcing experiment are investigated. As illustrated in Fig. 6,
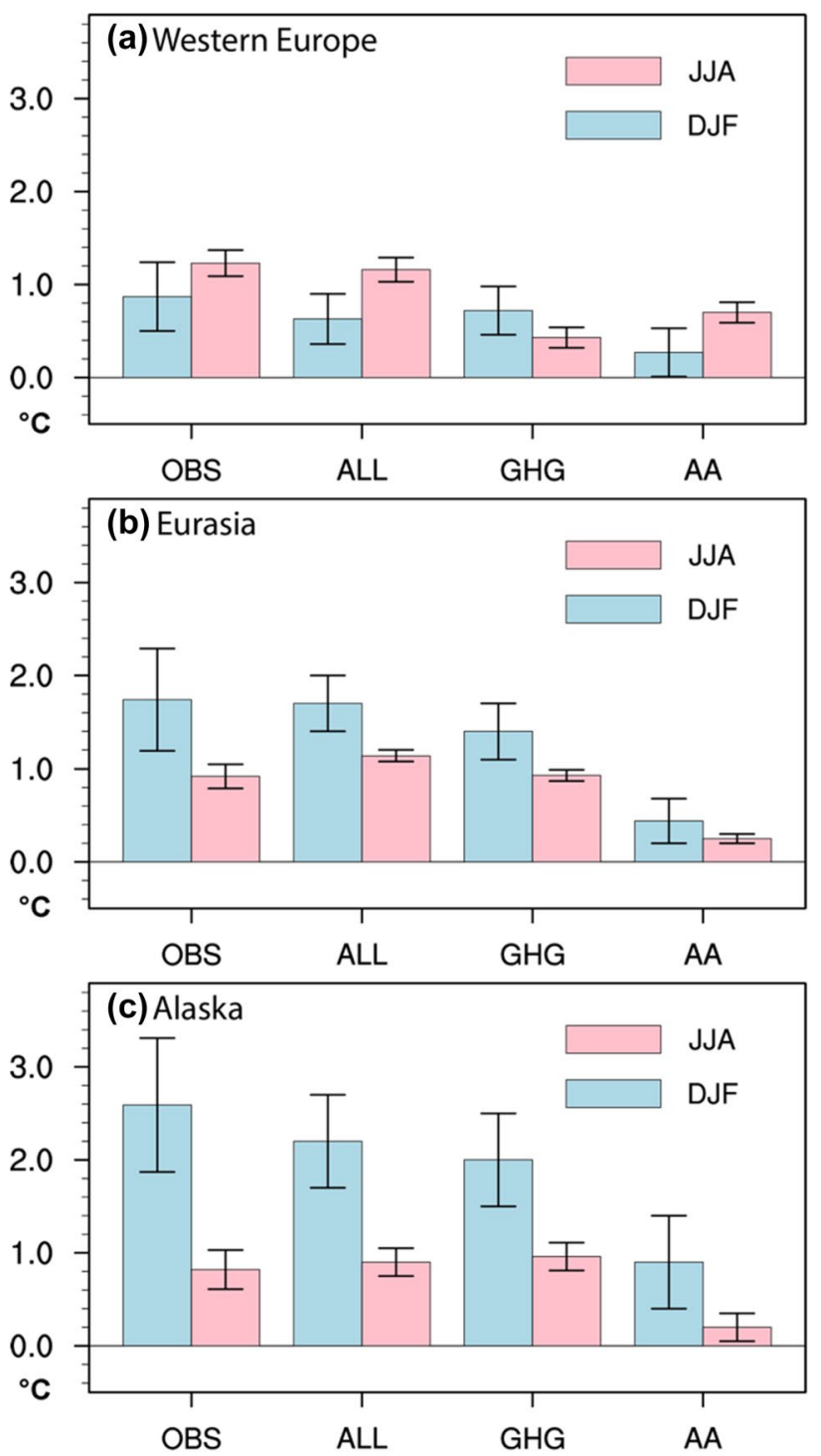

Fig. 5 Difference of SAT $\left({ }^{\circ} \mathrm{C}\right)$ between PD and EP in observations and model experiments in response to different forcings over a western Europe, b Eurasia, and c Alaska. Error bars represent the range between the average of the bootstrapped difference plus or minus one bootstrap standard error. OBS is observed change between PD and EP. ALL is the response to all forcing, GHG is the response to GHG and AA the response to AA forcing

the decrease in AA emissions over Europe from EP to PD induces a large decrease of aerosol optical depth (AOD) over Europe (Fig. 6b). The reduction of AOD increases local SAT through increasing the clear sky surface shortwave radiation (SW, Fig. 6c). Though the aerosol emissions have weak seasonality, climatologically greater precipitation and stronger wind in DJF leads to more wet deposition and transportation (Uematsu et al. 1983). Thus, the changes of aerosol burden and AOD are less in DJF (Fig. 7i) than in JJA (Fig. 6b). Moreover, the mean insolation in DJF is also weaker than in JJA. This process is consistent with Turnock et al. (2016), 


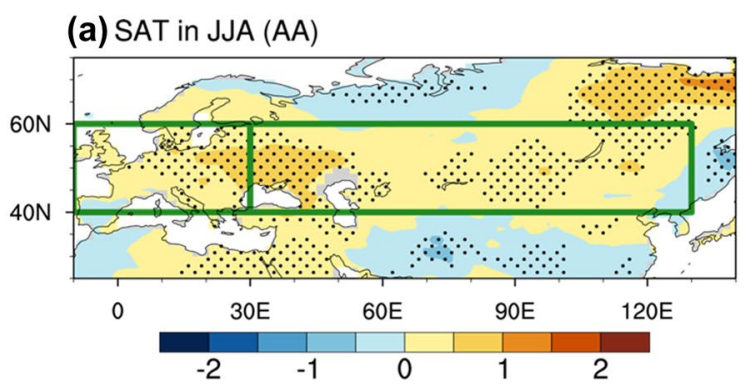

\section{(b) AOD in JJA (AA)}

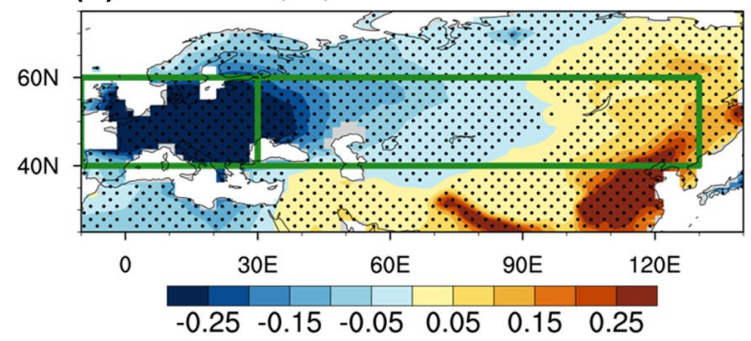

(d) Cloud cover in JJA (AA)

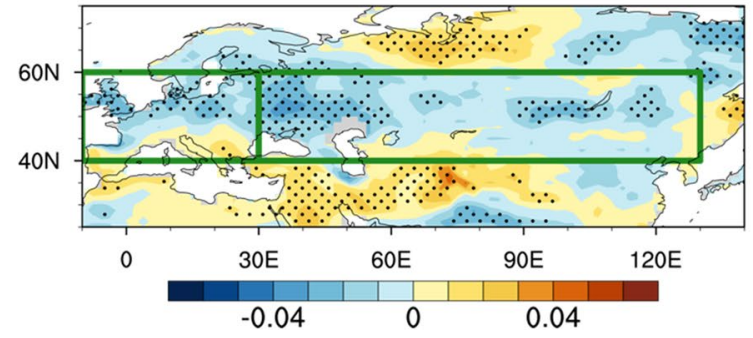

Fig. 6 Spatial patterns of changes in response to AA forcing in JJA. a Surface air temperature (SAT, ${ }^{\circ} \mathrm{C}$ ), b aerosol optical depth (AOD) and $\mathbf{c}$ clear sky net surface short wave radiation $\left(\mathrm{W} \mathrm{m}^{-2}\right.$, downward is positive), $\mathbf{d}$ cloud cover and e surface short wave cloud radiative

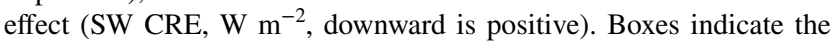

which shows that the reduction in aerosol concentrations increased the amount of solar radiation incident at the surface over Europe and increased European annual mean surface temperature by $0.45^{\circ} \mathrm{C}$. Therefore, increased clear sky surface $\mathrm{SW}$ resulting from a decrease in AA emissions is stronger in JJA than in DJF, and leading to stronger surface warming and therefore SAT change in JJA. These results are confirmed by the regional averaged surface radiation and turbulent heat fluxes shown in Table 2, which shows that the SAT warming in western Europe in response to AA forcing is dominated by the increased surface shortwave radiation, being mainly contributed by the increased clear sky SW.

\subsection{Eurasia}

Figure $5 \mathrm{~b}$ shows the regional mean SAT warming over Eurasia $\left(30^{\circ}-130^{\circ} \mathrm{E}, 40^{\circ}-60^{\circ} \mathrm{N}\right.$, land only). The observed warming is about $1.74{ }^{\circ} \mathrm{C}$ in DJF and $0.92{ }^{\circ} \mathrm{C}$ in JJA. This is consistent with the result in Huang et al. (2012), which shows that over semi-arid regions the warming trend in cold (c) Clear sky SW in JJA (AA)

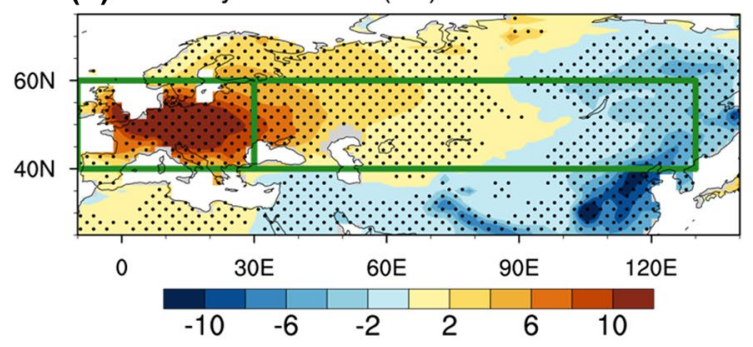

(e) SW CRE in JJA (AA)

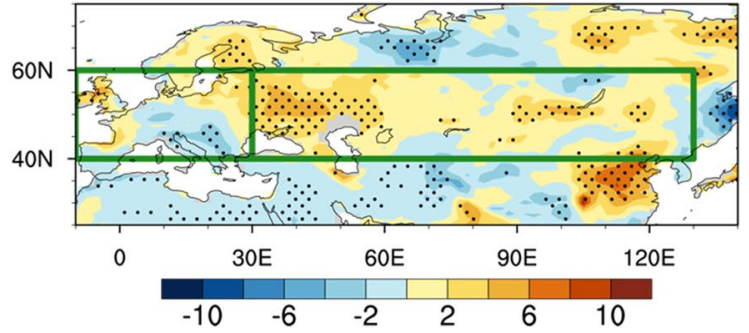

selected regions of western Europe $\left(10^{\circ} \mathrm{W}-30^{\circ} \mathrm{E}, 40^{\circ}-60^{\circ} \mathrm{N}\right)$ and Eurasia $\left(30^{\circ}-130^{\circ} \mathrm{E}, 40^{\circ}-60^{\circ} \mathrm{N}\right)$. Dots highlight regions where the changes are statistically significant at the $10 \%$ level using a two-tailed Student's $t$ test

seasons is enhanced. The seasonality of the SAT warming over Eurasia is well captured in the All-forcing experiments, although the simulated SAT warming is slightly larger than in observations in JJA.

As shown in Fig. 5b, the SAT warming in response to anthropogenic forcing is dominated by GHG forcing, which explains up to about $82 \%$ of the signal in response to the All forcing in both seasons. Another important feature is that both GHG forcing and AA forcing induce stronger warming in DJF than in JJA. In both seasons, the AA induced warming is weaker, and is unlikely to explain more than $25 \%$ of the warming seen in the All-forcing experiment. The sum of the warming from individual forcings is not exactly equal to the warming in the All-forcing experiment, because the effects of GHG and AA forcing are not linear. However, in this case, linear additivity is a good assumption: the sum of the AA and GHG driven warming is within $10 \%$ of the All forced case in both seasons and is well within the standard error of the All-forcing experiment. 


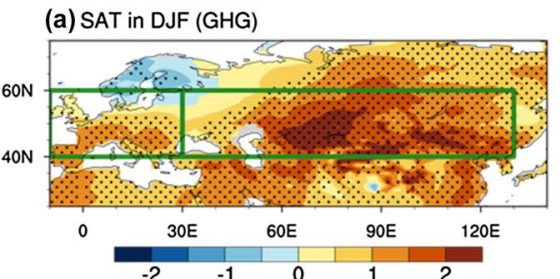

(d) SAT in DJF (AA)
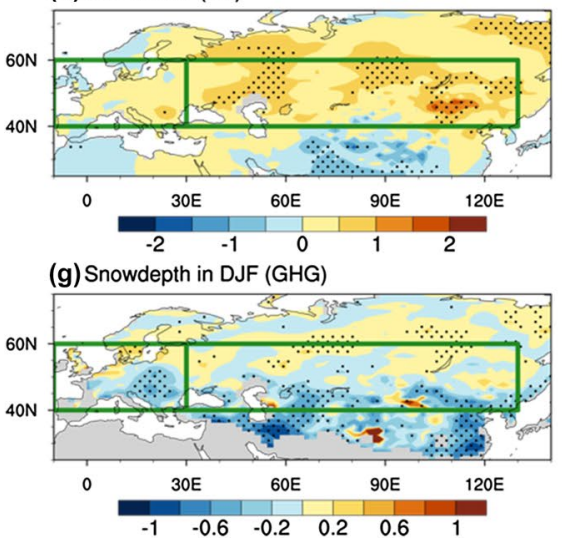

(b) Albedo in DJF (GHG)

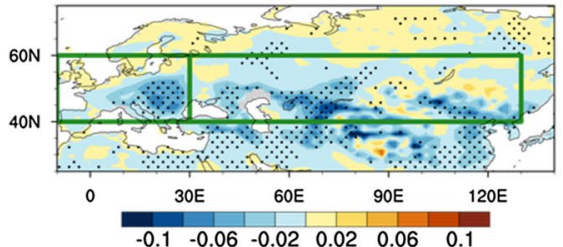

(e) Albedo in DJF (AA)

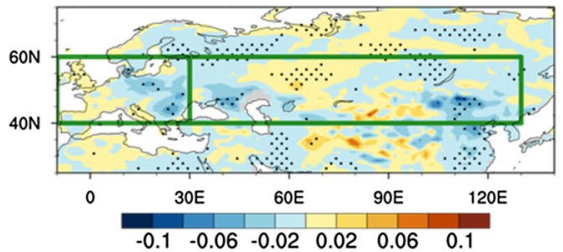

(h) Snowdepth in DJF (AA)

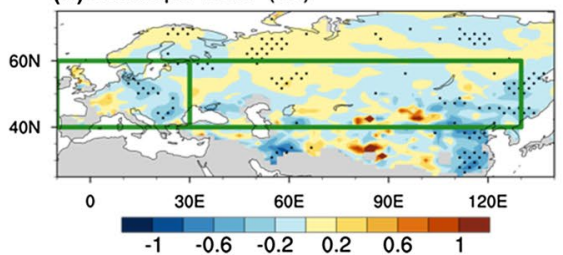

(c) Clear sky SW in DJF (GHG)

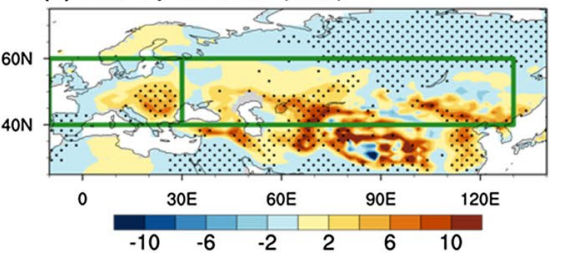

(f) Clear sky SW in DJF (AA)

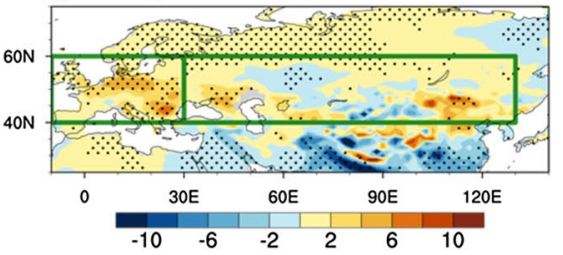

(i) AOD in DJF (AA)

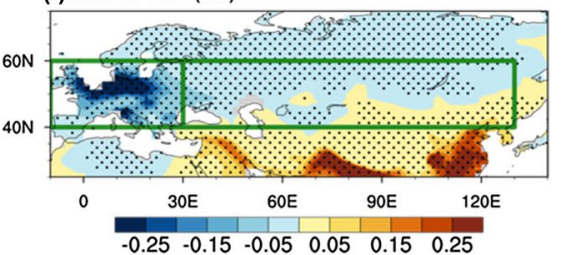

Fig. 7 Spatial patterns of changes in response to GHG forcing $(\mathbf{a}-\mathbf{c})$ and AA forcing (d-f) in DJF. a, d Surface air temperature (SAT, ${ }^{\circ} \mathrm{C}$ ), $\mathbf{b}$, e surface albedo and $\mathbf{c}, \mathbf{f}$ surface net clear sky short wave radiation ( $\mathrm{W} \mathrm{m}{ }^{-2}$, downward is positive). $\mathbf{g}$ Relative changes in snow depth in response to GHG forcing (100\%), h relative changes in snow depth in response to AA forcing (100\%) and $\mathbf{i}$ changes in aerosol optical depth (AOD) in response to AA-forcing. Boxes indicate the selected regions of western Europe $\left(10^{\circ} \mathrm{W}-30^{\circ} \mathrm{E}, 40^{\circ}-60^{\circ} \mathrm{N}\right)$ and Eurasia $\left(30^{\circ}-130^{\circ}\right.$ E, $\left.40^{\circ}-60^{\circ} \mathrm{N}\right)$. Dots highlight regions where the changes are statistically significant at the $10 \%$ level using a two-tailed Student's $t$ test
Table 2 Changes in surface air temperature (SAT in $\left.{ }^{\circ} \mathrm{C}\right)$, net surface short wave radiation (SW), net surface longwave radiation (LW), latent heat flux (LH), sensible heat flux (SH), clear sky shortwave radiation (SWCS), clear sky longwave radiation (LWCS), shortwave cloud radiative effect (SWCRE) and longwave cloud radiative effect (LWCRE) in $\mathrm{W} \mathrm{m}^{-2}$ with downward being positive

\begin{tabular}{lllllllrrrr}
\hline & Exp & SAT & \multicolumn{1}{l}{ SW } & \multicolumn{1}{l}{ LW } & LH & SH & SWCS & LWCS & SWCRE & LWCRE \\
\hline WE (JJA) & All & 1.13 & 11.43 & -2.11 & -4.05 & -2.37 & 7.50 & 0.09 & 3.93 & -2.20 \\
& GHG & 0.42 & 0.94 & 0.03 & -0.05 & 0.89 & -0.31 & 0.87 & 1.25 & -0.84 \\
& AA & 0.59 & 8.82 & -1.48 & -5.21 & -0.78 & 8.53 & -0.98 & 0.29 & -0.50 \\
EA (DJF) & All & 1.70 & 1.38 & 0.46 & -0.36 & -0.47 & 2.18 & -0.32 & -0.80 & 0.78 \\
& GHG & 1.42 & 0.91 & 0.71 & -0.34 & -0.34 & 1.57 & 0.14 & -0.66 & 0.57 \\
& AA & 0.44 & 0.50 & 0.04 & 0.06 & -0.06 & 0.61 & -0.31 & -0.11 & 0.35 \\
EA (JJA) & All & 1.11 & 2.52 & -1.16 & 0.53 & -1.39 & -0.46 & 0.46 & 2.98 & -1.62 \\
& GHG & 0.92 & 1.60 & -1.08 & 0.76 & -1.37 & -0.83 & 0.28 & 2.43 & -1.36 \\
& AA & 0.25 & 1.51 & -0.78 & 0.13 & -0.41 & 0.39 & -0.28 & 1.12 & -0.50 \\
\hline
\end{tabular}

The variables are averaged in western Europe (WE) in JJA and Eurasia (EA) in DJF and JJA. All, GHG and AA indicate the changes in response to All forcing, GHG forcing and AA forcing, respectively
To understand the enhanced warming over Eurasia in DJF, the spatial patterns of SAT warming induced by different forcings are shown in Fig. 7a, d, g, respectively. The GHG induced SAT warming (Fig. 7a) shows similar distribution to and explains a large proportion of the warming induced by All forcing (Fig. 2b), with the maximum in the centre and south region of Eurasia. The direct impact of GHG forcing can immediately induce warming via the greenhouse effect. In addition, this warming is associated with the reduction of surface albedo (Fig. 7b) due to decreased snow depth (Fig. $7 \mathrm{~g}$ ). The decreased surface albedo induces an increase of the net clear sky surface SW (Fig. 7c), which amplifies the SAT warming induced directly by increased GHG. The amplified SAT warming can further enhance the snow melting and leads to a positive feedback on surface warming. The importance of the changes in surface albedo in enhancing the SAT warming is confirmed by the regional averaged surface radiation and turbulent heat fluxes in Table 2. The SAT warming in Eurasia is strongly amplified by the increased $\mathrm{SW}$, which is mainly contributed by increased clear sky SW due to GHG forcing. 
Changes in AA forcing also induce SAT warming in DJF (Fig. 7d), though it is weaker than GHG-induced warming in Fig. 7a. The warming over Eurasia is initiated by the direct effect of the decrease of AA emission over Europe. Since the Eurasian continent is located downwind of western Europe, the reduction of AA emissions over Europe decreases the AOD over Eurasia (Fig. 7i). This leads to increases in net clear sky shortwave insolation and therefore net surface downward shortwave radiation, and then leads to surface warming and SAT increase. This warming induces a reduction of snow depth (Fig. 7h), which has positive feedback on aerosol-induced SAT change through a reduction in surface albedo (Fig. 7e). Due to the combined effect of reduction of AA emissions and the surface albedo, the surface clear sky SW increases (Fig. 7f), which is the dominant term in the surface energy components in AA forcing experiments (Table 2).

SAT warming in JJA due to the GHG forcing is associated with significant decreases in cloud cover and soil moisture (Fig. 8). The GHG induced SAT warming has a maximum in the central and north-eastern Eurasian continent $\left(60^{\circ}\right.$ E-90 ${ }^{\circ}$ E) (Fig. 8a), consistent with the decrease of cloud cover shown in Fig. 8b. The effect of the decrease of cloud cover is indicated by positive changes in the shortwave cloud radiative effect (SW CRE, Fig. 8d), leading to positive SW anomalies. As addressed in Boé and Terray (2014) and Dong et al. (2017a), the reduction of cloud cover over land is a feedback related to the enhanced surface warming over land relative to ocean.

Additionally, the SAT warming caused by the direct effect of GHG changes is associated with the decrease of soil moisture over Eurasian continent $\left(50^{\circ} \mathrm{E}-90^{\circ} \mathrm{E}\right)$ (Fig. 8f), where the climatological mean soil moisture is very small, within the range between $5-30 \mathrm{~kg} \mathrm{~m}^{-2}$ (Fig. 8e). The deficit of soil moisture constrains the evapotranspiration, which results in a decreased upward latent heat flux (LH) (Fig. 8g, downward is positive) and amplifies the GHG-induced SAT warming and also contributes to the reduction of cloud cover. The important role of feedbacks related to change in cloud cover and reduced soil moisture for the surface warming over Eurasia in JJA is further quantitatively demonstrated in Table 2.

The changes in AA forcing in summer also induce SAT warming over the Eurasian continent (Fig. 6a). Due to the decrease in AA emissions over western Europe, AOD decreases over a large region west of $90^{\circ} \mathrm{E}$ (Fig. 6b), inducing positive anomalies in clear sky SW (Fig. 6c; Table 2). Moreover, the decrease of AA emissions leads to a decrease in cloud droplet number concentration, increase of cloud droplet size, and shortened cloud lifetime, which is associated with the reduction of cloud cover over central Eurasia (Fig. 6d; Table 2). Interestingly, AOD changes show increases over eastern Eurasia and East Asia (Fig. 6b) due to increases of AA emissions in PD relative to EP. As demonstrated by Tian et al. (2018), the increase of local AA induces weakened East Asian summer monsoon circulation and decrease in cloud cover (Fig. 6d), leading to positive changes in SW CRE (Fig. 6e) that overwhelm the direct impact of increased local AA emissions, leading to surface and surface air warming over these two regions.

In summary, the SAT warming in DJF is larger than in JJA over Eurasia. The changes in GHG forcing leads to Eurasian surface warming through the greenhouse effect with positive snow albedo feedback in winter and positive cloud feedback in summer. The AA forcing induces the SAT warming by both aerosol-radiation and aerosol-cloud interactions, with positive snow-albedo feedback in winter and positive land surface and cloud feedbacks in summer.

\subsection{Alaska}

As shown in Fig. 2a, the primary feature over Alaska is that the SAT warming in DJF is extremely large relative to the surrounding area. Moreover, the warming in DJF is much larger than in JJA (Fig. 2c). The regional mean SAT warming over Alaska $\left(170^{\circ}-130^{\circ} \mathrm{W}, 60^{\circ}-70^{\circ} \mathrm{N}\right.$, land only) is summarised in Fig. 5c. In observations, the SAT increases by $0.82^{\circ} \mathrm{C}$ in JJA. In DJF, however, it increases by $2.59^{\circ} \mathrm{C}$; three times stronger than in JJA. The warming and seasonality are simulated in the All forcing experiments, though the magnitude of DJF warming in the simulation is $0.4{ }^{\circ} \mathrm{C}$ weaker than in observations while in JJA it is $0.1^{\circ} \mathrm{C}$ more than in observations. Both GHG and AA forcing changes contribute to warming over Alaska in DJF. The warming due to GHG forcing is more than two times of the warming caused by AA forcing. In JJA, the warming due to AA forcing is very weak, and of a comparable size to noise. As shown in Fig. 3e, the simulated climatological mean SAT over Alaska has cold bias in DJF. The cold bias might lead to a weaker sensitivity to anthropogenic forcing (Overland and Wang 2007; Kattsov and Sporyshev 2006; Walsh et al. 2008).

Since Alaska is at high latitude, it is perhaps surprising that the winter warming amplification from EP to PD is well captured in our mixed layer model simulations as sea-ice feedback, which is very important for surface warming in the high-latitude regions (Screen and Simmonds 2010), is not included in our model.

To understand this strong local warming amplification in winter, we investigated the simulated spatial pattern of DJF mean changes for the SAT and related variables. The predominant change in surface energy components associated with warming in the All experiments is the increase in longwave cloud radiative effect (LW CRE) (Fig. 9b, f, j). The changes in LW CRE are related to the increase in cloud cover (Fig. 9c, g, k). The increased cloud cover is consistent with the local increase of water vapor in the 


\section{(a) SAT in JJA (GHG)}

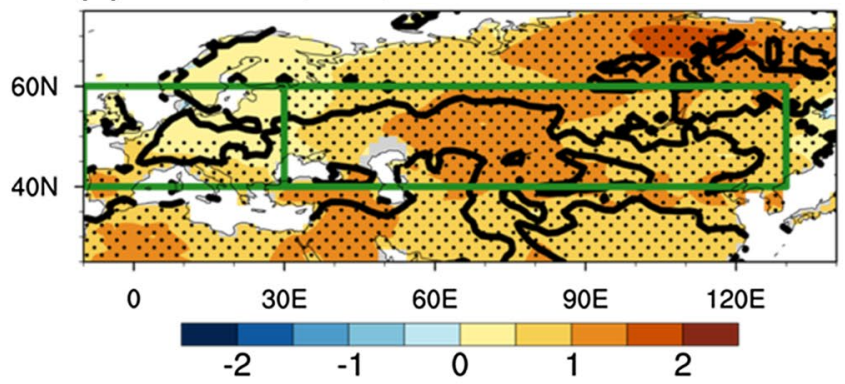

(b) Cloud cover in JJA (GHG)

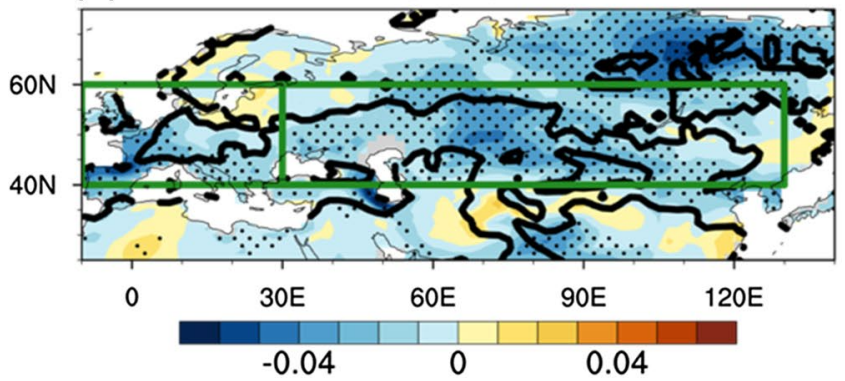

(d) SW CRE in JJA (GHG)

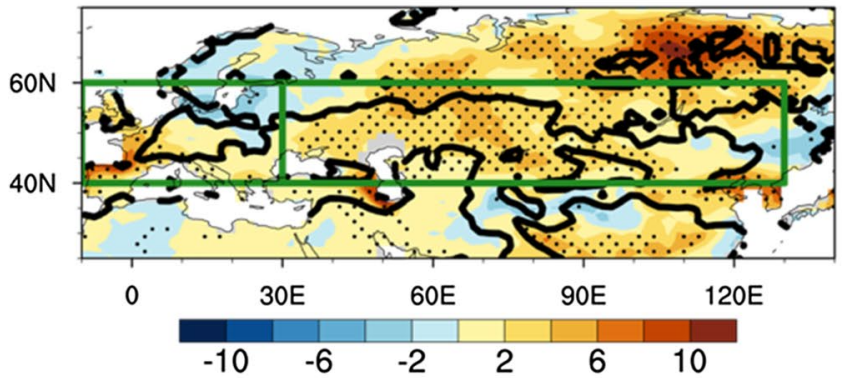

(f) Soil moisture in JJA (GHG)

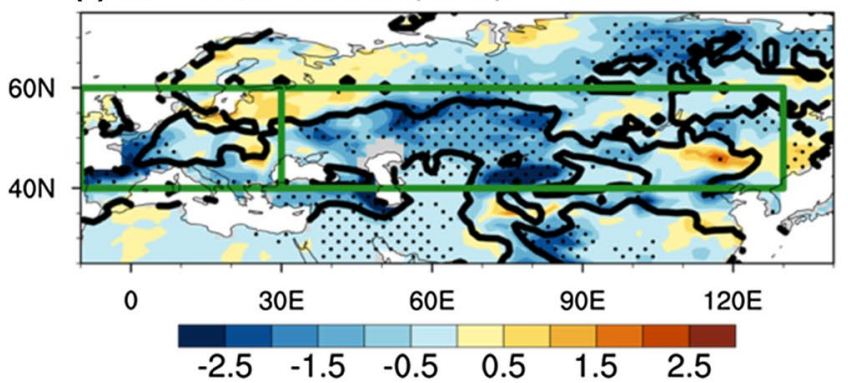

Fig. 8 Spatial patterns of changes in response to GHG forcing in JJA. a Surface air temperature $\left(\mathrm{SAT},{ }^{\circ} \mathrm{C}\right), \mathbf{b}$ cloud cover, c $700 \mathrm{hPa}$ relative humidity (\%), d surface short wave cloud radiative effect (SW CRE, $\mathrm{W} \mathrm{m}{ }^{-2}$, downward is positive), $\mathbf{f}$ soil moisture $\left(\mathrm{kg} \mathrm{m}^{-2}\right)$, $\mathbf{g}$ latent heat flux ( $\mathrm{W} \mathrm{m}^{-2}$, downward is positive). e Climatological soil moisture $\left(\mathrm{kg} \mathrm{m}^{-2}\right)$. Thick black contours highlight regions with soil moisture

atmosphere (Fig. 9d, h, 1). Both increased LW CRE and water vapor can amplify the SAT warming. Note that the SAT warming in Fig. 9e is the combination of the warming from the greenhouse effect and local feedbacks. Therefore, though the increased LW CRE due to AA forcing (Fig. 9j) (c) $700 \mathrm{hPa} \mathrm{RH}$ in JJA (GHG)

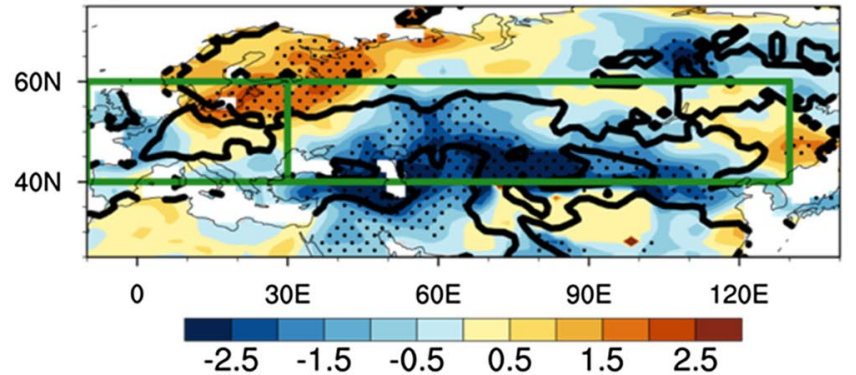

(e) Soil moisture in JJA (Climate)

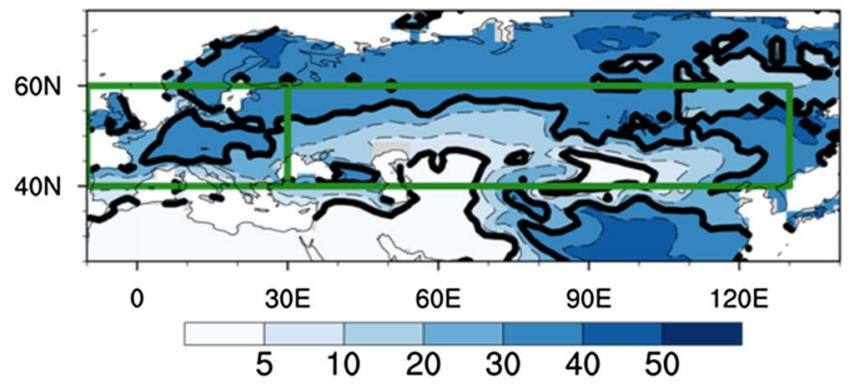

(g) Latent heat flux in JJA (GHG)

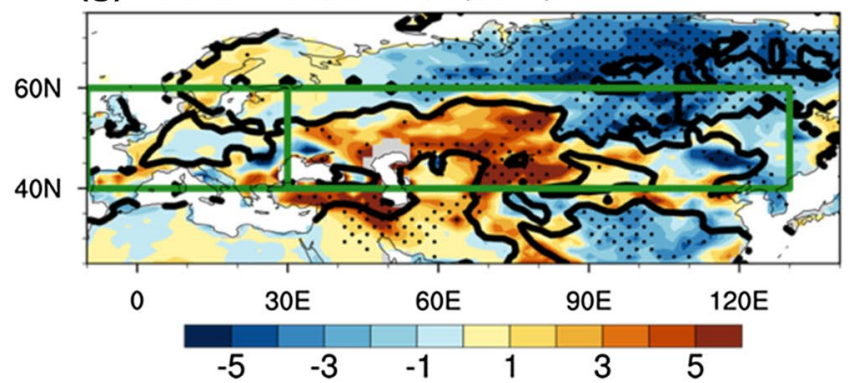

between 5-30 $\left(\mathrm{kg} \mathrm{m}^{-2}\right)$. Boxes indicate the selected regions of western Europe $\left(10^{\circ} \mathrm{W}-30^{\circ} \mathrm{E}, 40^{\circ}-60^{\circ} \mathrm{N}\right)$ and Eurasia $\left(30^{\circ}-130^{\circ} \mathrm{E}\right.$, $40^{\circ}-60^{\circ} \mathrm{N}$ ). Dots for responses highlight regions where the changes are statistically significant at the $10 \%$ level using a two-tailed Student's $t$ test

is stronger than that due to GHG forcing (Fig. 9f), the SAT warming due to GHG forcing (Fig. 9e) is much stronger than that due to AA forcing (Fig. 9i). The relationship between Alaska SAT warming in winter and the increase 

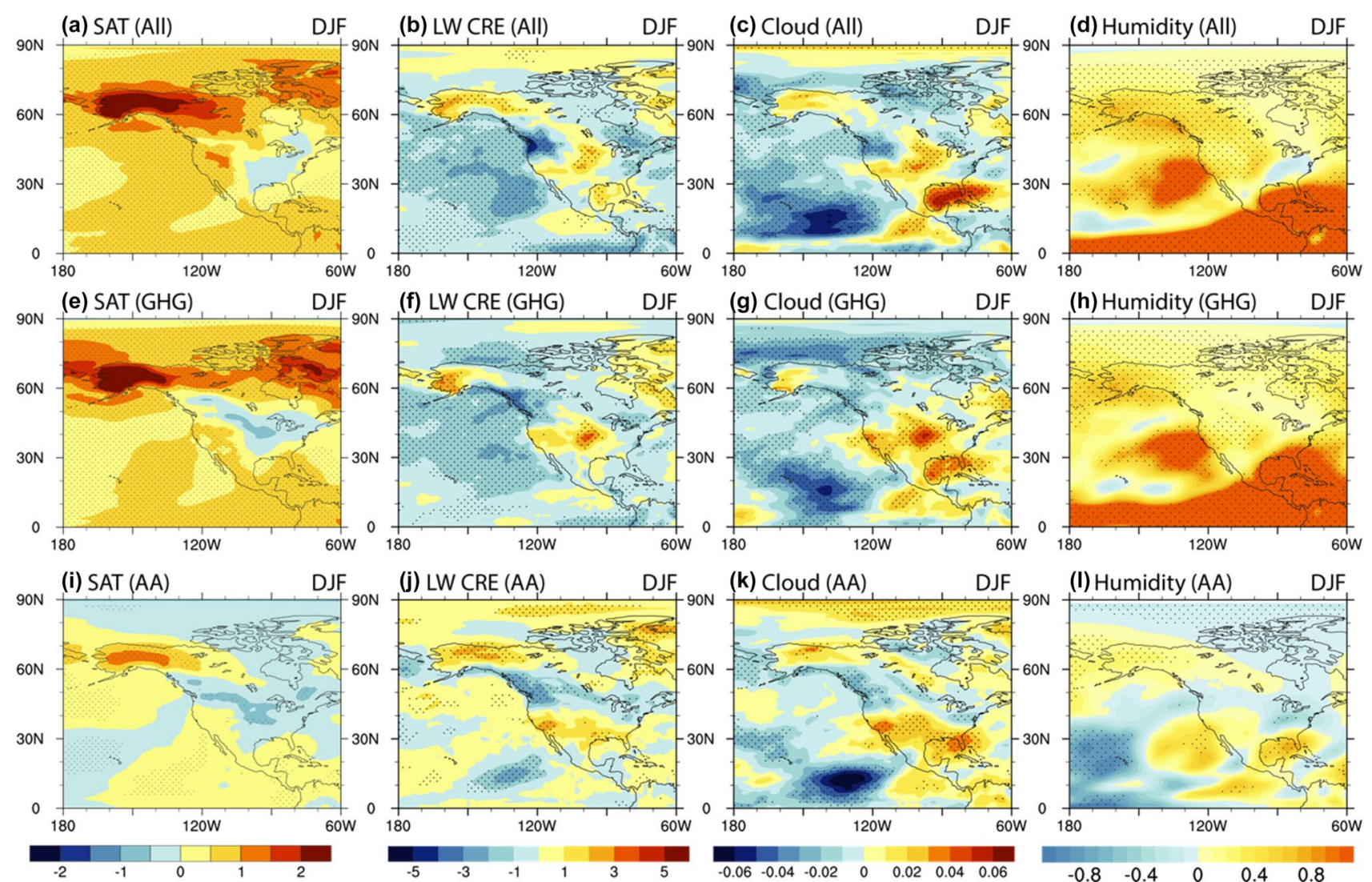

Fig. 9 Spatial patterns of changes in response to All forcing (top row), GHG forcing (middle row) and AA forcing (bottom row) in DJF. a, e, i Surface air temperature (SAT, $\left.{ }^{\circ} \mathrm{C}\right), \mathbf{b}, \mathbf{f}, \mathbf{j}$ surface longwave cloud radiative effect (LW CRE, downward is positive, $\mathrm{W} \mathrm{m}^{-2}$ ),

of local cloud cover is consistent with observations (L'Heureux et al. 2004).

What processes are responsible for the increase of cloud cover and water vapor in the atmosphere shown in Fig. 9? In observations, the North Pacific SST anomaly has a maximum centred over the North Pacific around $50^{\circ} \mathrm{N}$ and a minimum centred at $40^{\circ} \mathrm{N}$ (Fig. 10a), which is associated with an enhanced low and cyclonic wind anomaly at 925 $\mathrm{hPa}$ (Fig. 11a). This anomalous circulation is consistent with the circulation response to the local positive SST anomaly in the sensitivity study by Hu and Guan (2018). This southeasterly wind anomaly south of Alaska can transport more water vapor to the land and contribute to increased cloud cover there (L'Heureux et al. 2004).

Though the south-easterly wind anomaly at the south of Alaska is seen in both observations and the model simulations, the large-scale SST and wind anomalies are different. As shown in Fig. 10b, in the All-forcing experiments, the North Pacific SST has a local warm anomaly off the Alaskan coast, which is consistent with the centre of the anomalous low SLP and cyclonic circulation anomaly in Fig. 11b. However, the amplitude and pattern of SST warming over the $\mathbf{c}, \mathbf{g}, \mathbf{k}$ Cloud cover, and $\mathbf{d}, \mathbf{h}, \mathbf{l}$ vertical integrated specific humidity $\left(\mathrm{kg} \mathrm{m}^{-2}\right)$. Dots highlight regions where the changes are statistically significant at the $10 \%$ level using a two-tailed Student's $t$ test

wider North Pacific is very different between the model and observations, which much greater warming in the eastern basin in the model. This is consistent with the overestimation of the magnitude and extent of the low SLP anomaly in the model. Additionally, only a small region of cooling is seen, and in a different location to observations: around $25^{\circ}$ $\mathrm{N}$ over the western North Pacific (Fig. 11a). Furthermore, the modelled SST anomaly exhibits an El Niño-like pattern not seen in observations.

In the simulations, both GHG and AA forcings contribute to the low SLP anomaly and the related cyclonic circulation anomalies over the northern Pacific. The high latitude SST warming, and the associated SLP decrease, have similar spatial patterns in response to GHG and AA, but have a larger magnitude in response to GHG forcing (Figs. 10c, d, 11c, d).

Due to the prevailing north-westerly over the Asian continent in winter, aerosol emissions over Asia are transported to the subtropical North Pacific (Dong et al. 2019), leading to an increase in AOD (Fig. 12a) and cloud droplet number concentration (Fig. 12b), and decrease in cloud droplet effective radius (Fig. 12c). These changes lead to reduced surface net shortwave radiation and result in SST cooling. 

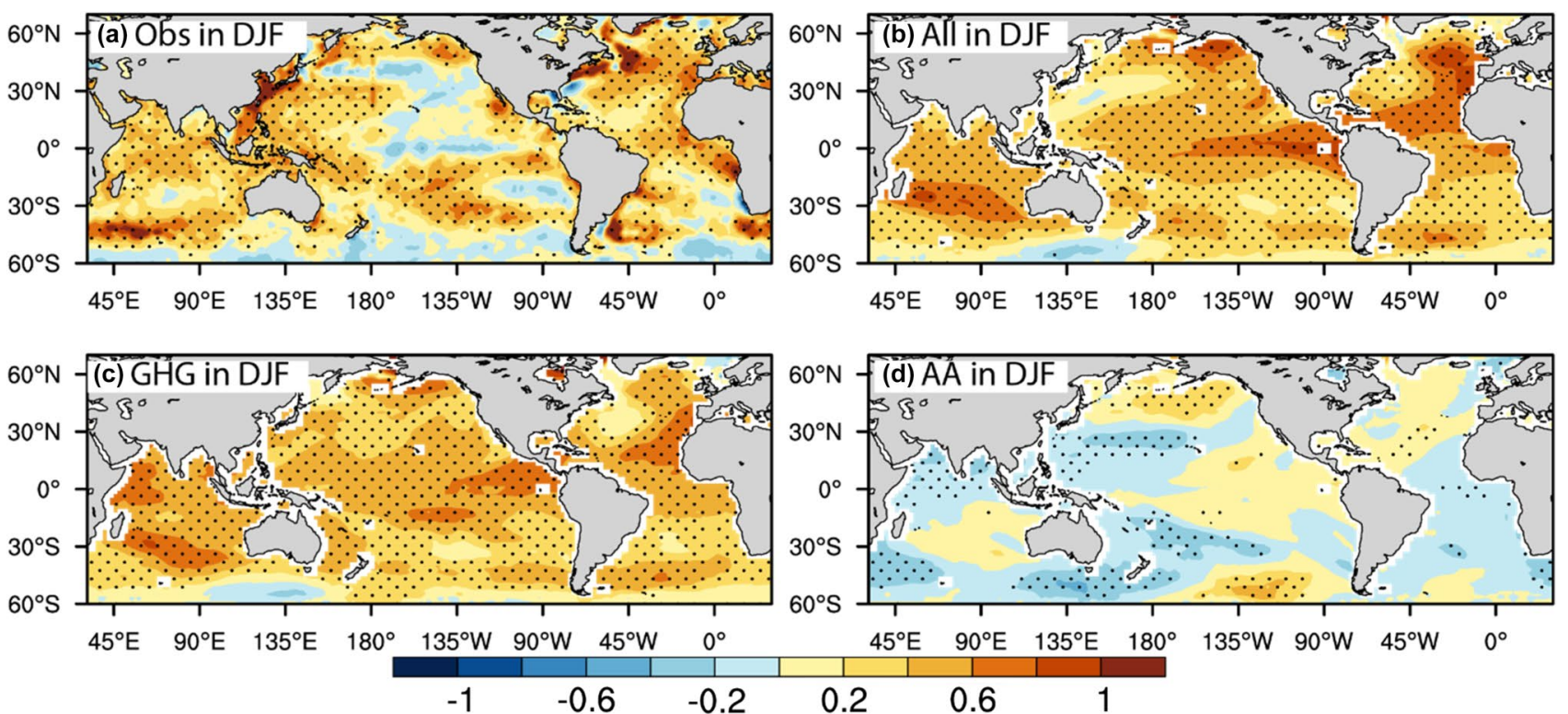

Fig. 10 Spatial patterns of changes in SST $\left({ }^{\circ} \mathrm{C}\right) \mathbf{a}$ in observations, and in response to $\mathbf{b}$ All forcing, $\mathbf{c}$ GHG forcing, and $\mathbf{d}$ AA forcing in DJF. Dots highlight regions where the changes are statistically significant at the $10 \%$ level using a two-tailed Student's $t$ test
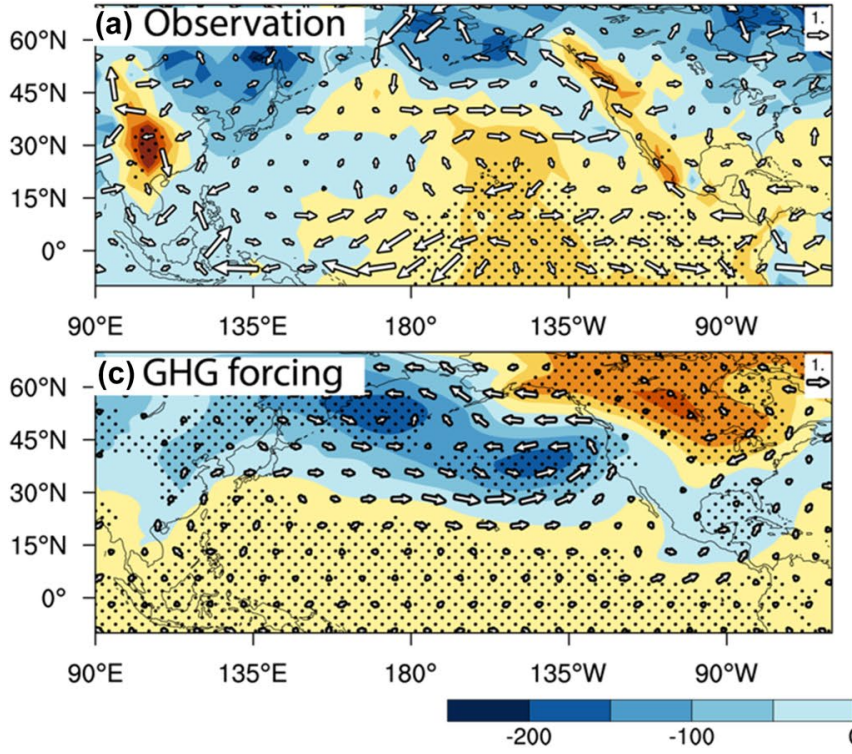

Fig. 11 Spatial patterns of changes in SLP (Pa) and $925 \mathrm{hPa}$ wind ( $\mathrm{m}$ $\mathrm{s}^{-1}$, arrows) for a changes in observations, and in response to $\mathbf{b}$ All forcing, $\mathbf{c}$ GHG forcing, d AA forcing in DJF. Dots highlight regions

In the model, this cooling in the western tropical Pacific leads to a weakened zonal SST gradient, and results in El Nino-like SST anomalies over the tropical Pacific. Consistent with Renwick and Wallace (1996) and Gan et al. (2017), the modelled El Nino-like SST anomalies are related to the enhanced Aleutian Low and cyclonic wind anomalies over the North Pacific (Fig. 10c).
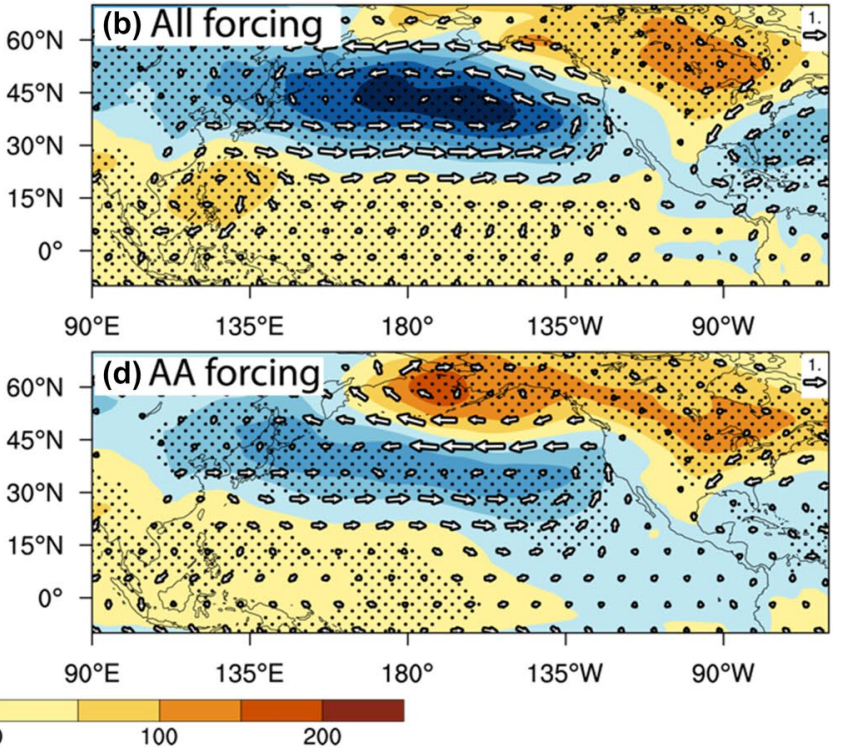

where the changes of SLP are statistically significant at the $10 \%$ level using a two-tailed Student's $t$ test

Since Alaska is at high latitudes, snow-albedo feedback is expected to play an important role in winter warming in response to GHG increases. To clarify the effect of snow-albedo feedback over Alaska, we have analysed the changes in snow depth and clear sky SW in DJF. The result shows that the snow depth is decreased due to the GHG induced warming. However, the clear sky SW is only slightly decreased, suggesting that the decrease 


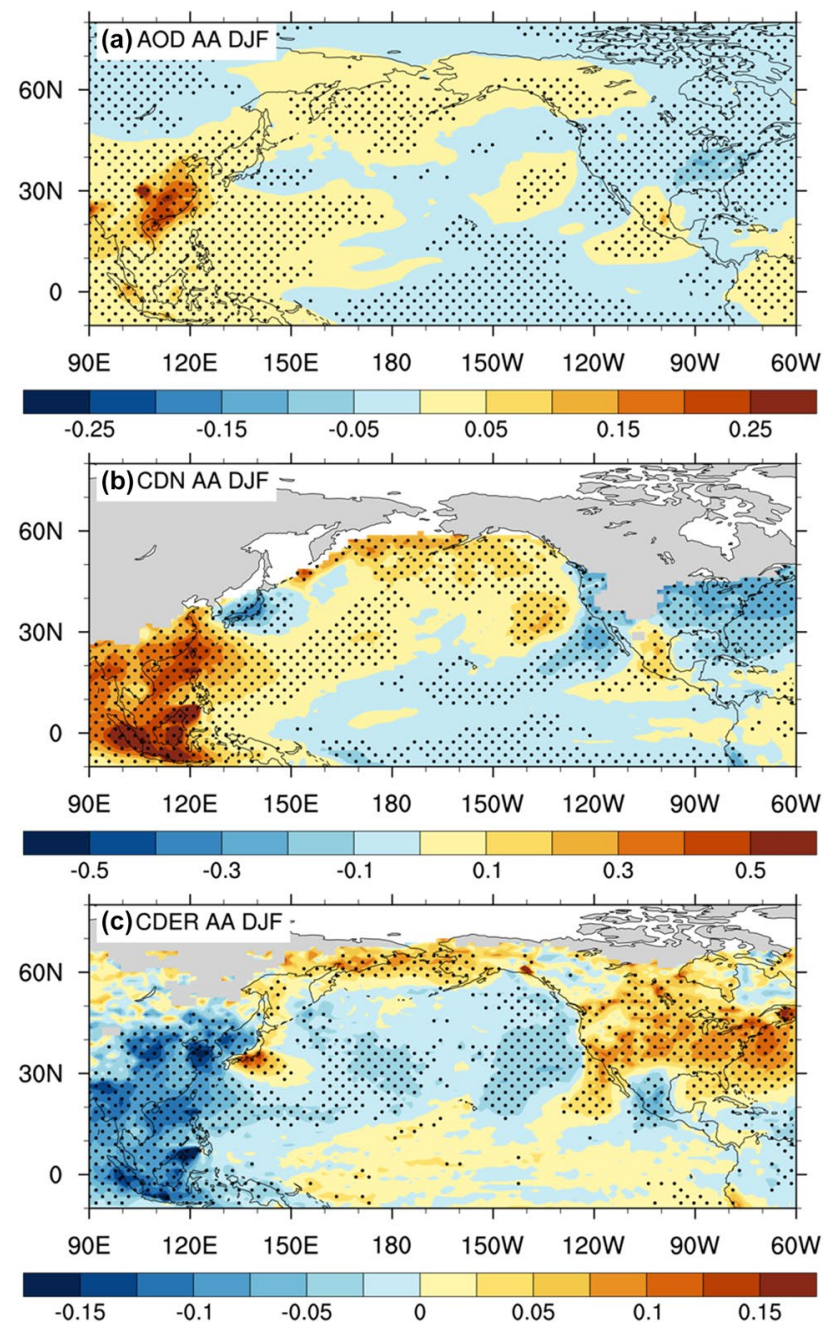

Fig. 12 Spatial patterns of changes in $\mathbf{a}$ AOD, $\mathbf{b}$ cloud droplet number concentration (CDNC in $10^{10} \mathrm{~m}^{-2}$ ) and $\mathbf{c}$ cloud droplet effective radius (CDER in $\mu \mathrm{m}$ ) in DJF in response to AA forcing. CDNC and CDER are ratio of changes relative to the climatology. Dots highlight regions where the changes are statistically significant at the $10 \%$ level using a two-tailed Student's $t$ test

of snow depth does not lead to the decrease of surface albedo. The simulated climatological snow depth is about ten times more than the melted part due to GHG forcing (not shown), thus, in the model, the snow-albedo feedback is not a contributing factor for Alaska warming in winter. The slight decrease in clear sky SW radiation might be associated with the increase of moisture in the atmosphere, which increases solar radiation absorption (e.g., Mitchell et al. 1987).

In summary, the amplified surface warming in winter over Alaska is related to the increased water vapor and cloud cover, which amplify the surface LW CRE. However, the processes leading to the increased cloud cover are different between model simulations and observations. In the model simulations, it is related to an El Nino-like SST anomalies in the tropical Pacific, which is contributed by both the GHG forcing and AA forcing. These SST anomalies are associated with an enhanced Aleutian Low (consistent with Gan et al. 2017) and increased transport of water vapor from the North Pacific to Alaska. However, in observations, the tropical SST changes show a pattern with warm anomaly in west and cold- anomaly in east (Fig. 10a), which is opposite to the simulated El Nino-like SST anomalies.

Over Alaska, we have shown that the model is able to reproduce the observed temperature anomaly, but the largerscale circulation pattern simulated by the model does not agree with observations. A tendency for El Niño-like warming of tropical SST anomalies like those seen in our experiment is seen in most coupled GCMs and may be due to that the local SST is too sensitive to the radiative forcing (Seager et al. 2019).

\section{Conclusions and discussion}

Observed surface air temperature (SAT) changes over land in the period 1960-2010 showed non-uniform warming, with amplified warming over western Europe, Eurasia, and Alaska, with some distinct seasonal variations. Based on a set of time-slice experiments using MetUM-GOML1, we identified the physical processes that have plausibly contributed to the amplified SAT warming over these regions and quantified the roles of different components of anthropogenic forcing, i.e., changes in greenhouse gases (GHG) forcing and anthropogenic aerosol (AA) emissions. Our principal results are summarized schematically in Fig. 13 and listed as follows:

1 The spatial distribution and seasonality of the SAT warming over western Europe, Eurasia and Alaska in observations are well simulated by the MetUM-GOML1 when forced by corresponding changes in GHG and AA emissions.

2 The warming in western Europe is stronger in JJA than in DJF. The AA forcing, which has a larger effect in JJA, is required to explain the seasonality. In JJA, a decrease in aerosol optical depth (AOD), due to the reduced aerosol emissions over Europe, induces increase in clear sky SW that warms land surface and SAT. In addition, reduced AA emissions lead to a decrease in cloud condensation nuclei and result in positive SW CRE through both aerosol-cloud interactions and an aerosol-induced soil-moisture feedback. In DJF, smaller changes in AOD and weaker SW result in smaller subsequent changes in surface SW radiation over western Europe compared to JJA. The major processes are summarized in Fig. 13a.

3 The warming over Eurasia is stronger in DJF than in JJA. This seasonality is mainly driven by GHG forcing 
(a) Europe in JJA

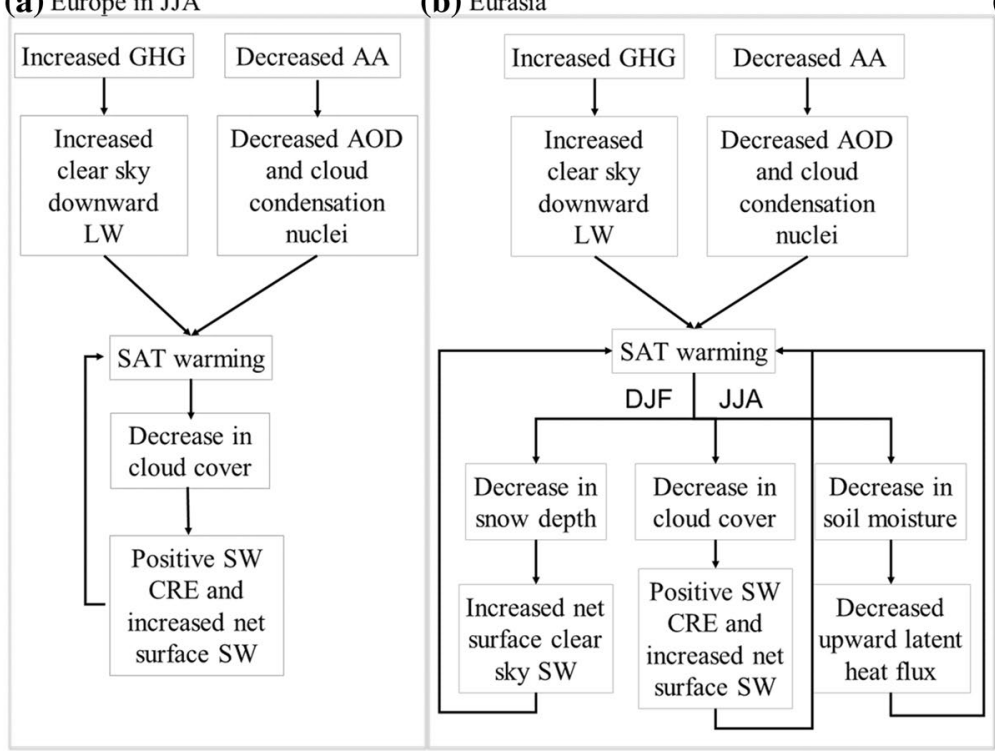

(c) Alaska in DJF

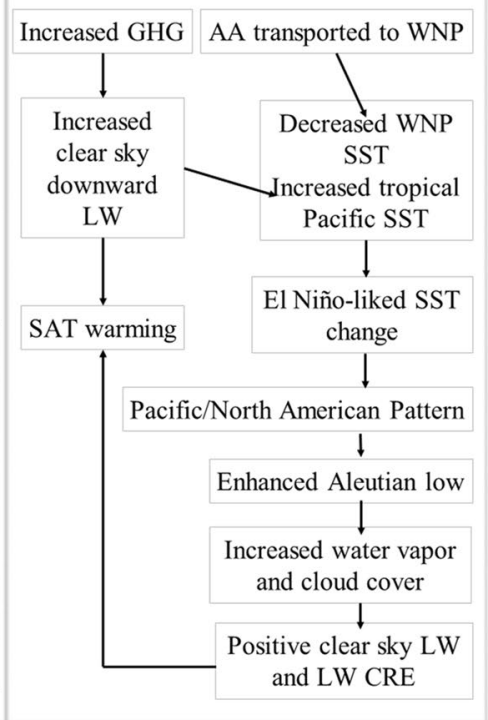

Fig. 13 Schematic diagram illustrating the major physical processes related to the local warming over a western Europe, $\mathbf{b}$ Eurasia and $\mathbf{c}$ Alaska

with small contribution from AA forcing, due to forcing induced positive snow-albedo feedbacks. AA changes induce a band of midlatitudes warming in JJA due to feedbacks related to the decrease in cloud cover and soil moisture. The decreased cloud cover leads to positive anomalies of SW CRE and, therefore, increases the surface net SW radiation. Reduced soil moisture leads to the reduction of upward LH flux. The major processes are summarized in Fig. 13b.

4 Over Alaska, enhanced warming in DJF is contributed to by both GHG and AA forcing in model simulations through changes in atmospheric large-scale circulation. Simulated changes in GHG and AA forcing are associated with El-Niño-like SST anomalies in the tropical Pacific, which appears to enhance the Aleutian low and increase the transport of water vapor from the North Pacific to Alaska. The increased water vapor and cloud cover amplify surface and SAT warming in response to GHG forcing and contribute to the warming in response to AA forcing (Fig. 13c).

Although the model simulates an important role for atmospheric circulation response, we note that the SST response over the North Pacific is different to observed changes (Fig. 10a, b). The large-scale atmospheric circulation response over the Pacific and, hence, Alaska is not the same as that seen in observations (Fig. 11a, b). These differences may be related to the formulation of the model. For example, sea ice is prescribed and so the simulations do not include the recent decrease of sea ice extent in the Arctic which was suggested to have played an important role for enhanced polar warming
(Screen and Simmonds 2010). The ocean model is also not fully dynamical, and so the SST patterns that generate the atmospheric response may be different in other models. Therefore, to fully understand past regional changes in SAT, and to ensure robust projections of future changes, it is important that the robustness of these results is explored in other models and fully coupled atmosphere-ocean general circulation models (CGCMs). Ultimatly, this case study of boreal winter warming over Alaska demonstrates potential issues in the detection and attribution of observed events when the models can reproduce them for the wrong reasons. Therefore, these results highlight the need to consider a model's ability to reproduce both the change in the variable of interest and the related processes if the model is to be used for projections.

Nevertheless, the results presented here highlight the importance of regional feedbacks in simulating the SAT response to both GHG and AA forcing. These results give further support to the important role of recent changes in anthropogenic aerosol emissions for the regional amplification of forced SAT changes over western Europe and Eurasia, but through different physical processes. The results also highlight how large-scale changes in atmospheric circulation in response to forcing can play an important role in modulating regional surface warming patterns in different seasons.

Acknowledgements This work is supported by UK-China Research and Innovation Partnership Fund through the Met Office Climate Science for Service Partnership (CSSP) China as part of the Newton Fund (Grant no. H5215700). BD, JR, and RS are supported by the U.K. National Centre for Atmospheric Science-Climate (NCAS-Climate) at the University of Reading. The authors would like to thank three 
anonymous reviewers for their constructive comments on the earlier version of the paper.

Open Access This article is licensed under a Creative Commons Attribution 4.0 International License, which permits use, sharing, adaptation, distribution and reproduction in any medium or format, as long as you give appropriate credit to the original author(s) and the source, provide a link to the Creative Commons licence, and indicate if changes were made. The images or other third party material in this article are included in the article's Creative Commons licence, unless indicated otherwise in a credit line to the material. If material is not included in the article's Creative Commons licence and your intended use is not permitted by statutory regulation or exceeds the permitted use, you will need to obtain permission directly from the copyright holder. To view a copy of this licence, visit http://creativecommons.org/licenses/by/4.0/.

\section{References}

Arribas A, Glover M, Maidens A, Peterson K, Gordon M, MacLachlan C, Graham R, Fereday D, Camp J, Scaife AA, Xavier P, McLean P, Colman A, Cusack S (2011) The GloSea4 ensemble prediction system for seasonal forecasting. Mon Weather Rev 139(6):1891-1910

Bayr T, Dommenget D (2013) The tropospheric land-sea warming contrast as the driver of tropical sea level pressure changes. J Clim 26(4):1387-1402

Bellouin N, Boucher O, Haywood J, Johnson C, Jones A, Rae J, Woodward S (2007) Improved representation of aerosols for HadGEM2. Hadley Cent Tech Note 73:43

Boucher O, Randall D, Artaxo P, Bretherton C, Feingold G, Forster P, Kerminen VM, Kondo Y, Liao H, Lohmann U, Rasch P, Satheesh SK, Sherwood S, Stevens B, Zhang X (2013) Clouds and aerosols. In: Stocker T et al (eds) Climate change 2013: the physical science basis. Contribution of Working Group I to the Fifth Assessment Report of the Intergovernmental Panel on Climate Change. Cambridge University Press, Cambridge, pp 571-657

Boé J, Terray L (2014) Land-sea contrast, soil-atmosphere, and cloud temperature interactions: interplays and roles in future summer European climate change. Clim Dyn 42:683-699

Chen W, Dong B (2018) Anthropogenic impacts on recent decadal change in temperature extremes over China: relative roles of greenhouse gases and anthropogenic aerosols. Clim Dyn. https ://doi.org/10.1007/s00382-018-4342-9

Chen L, Frauenfeld OW (2014) Surface air temperature changes over the twentieth and twenty-first centuries in China simulated by 20 CMIP5 models. J Clim 27(11):3920-3937

Christidis N, Stott PA, Brown SJ (2011) The role of human activity in the recent warming of extremely warm daytime temperatures. J Clim 24(7):1922-1930

Dai A, Fyfe JC, Xie SP, Dai X (2015) Decadal modulation of global surface temperature by internal climate variability. Nat Clim Change 5(6):555

Dong B, Gregory JM, Sutton RT (2009) Understanding land-sea warming contrast in response to increasing greenhouse gases. Part I: Transient adjustment. J Clim 22(11):3079-3097

Dong B, Sutton RT, Shaffrey L (2017a) Understanding the rapid summer warming and changes in temperature extremes since the mid-1990s over Western Europe. Clim Dyn 48(5-6):1537-1554

Dong B, Sutton RT, Shaffrey L, Klingaman NP (2017b) Attribution of forced decadal climate change in coupled and uncoupled ocean-atmosphere model experiments. J Clim 30(16):6203-6223
Dong B-W, Wilcox L, Highwood E, Sutton R (2019) Impacts of recent decadal changes in Asian aerosols on the East Asian summer monsoon: roles of aerosol-radiation and aerosol-cloud interactions. Clim Dyn (revised)

Efron B, Tibshirani RJ (1994) An introduction to the bootstrap. CRC press

Feldman DR, Collins WD, Gero PJ, Torn MS, Mlawer EJ, Shippert TR (2015) Observational determination of surface radiative forcing by $\mathrm{CO}_{2}$ from 2000 to 2010. Nature 519(7543):339

Gan B, Wu L, Jia F, Li S, Cai W, Nakamura H, Alexander MA, Miller AJ (2017) On the response of the Aleutian low to greenhouse warming. J Clim 30(10):3907-3925

Harris IPDJ, Jones PD, Osborn TJ, Lister DH (2014) Updated highresolution grids of monthly climatic observations - the CRU TS3. 10 DaSATet. Int J Climatol 34(3):623-642

Hauser M, Gudmundsson L, Orth R, Jézéquel A, Haustein K, Vautard R, Van Oldenborgh GJ, Wilcox L, Seneviratne SI (2017) Methods and model dependency of extreme event attribution: the 2015 European drought. Earth's Future 5(10):1034-1043

Hirons LC, Klingaman NP, Woolnough SJ (2015) MetUM-GOML: a near-globally coupled atmosphere-ocean-mixed-layer model. Geosci Model Dev 8:363-379

$\mathrm{Hu}$ D, Guan Z (2018) Decadal relationship between the stratospheric Arctic vortex and Pacific Decadal Oscillation. J Clim 31(9):3371-3386

Huang JP, Guan XD, Ji F (2012) Enhanced cold-season warming in semi-arid regions. Atmos Chem Phys 12(12):5391-5398

Ji F, Wu Z, Huang J, Chassignet EP (2014) Evolution of land surface air temperature trend. Nat Clim Change 4(6):462

Jones C, Hughes JK, Bellouin N, Hardiman SC, Jones GS, Knight J, Boo KO et al (2011) The HadGEM2-ES implementation of CMIP5 centennial simulations. Geosci Model Dev 4(3):543-570

Joshi MM, Gregory JM, Webb MJ, Sexton DM, Johns TC (2008) Mechanisms for the land/sea warming contrast exhibited by simulations of climate change. Clim Dyn 30(5):455-465

Kattsov VM, Sporyshev PV (2006) Timing of global warming in IPCC AR4 AOGCM simulations. Geophys Res Lett 33:L23707. https:// doi.org/10.1029/2006GL027476

Knutson TR, Zeng F, Wittenberg AT (2013) Multimodel assessment of regional surface temperature trends: CMIP3 and CMIP5 twentieth-century simulations. J Clim 26(22):8709-8743

Lamarque JF, Bond TC, Eyring V, Granier C, Heil A, Klimont Z, Schultz MG et al (2010) Historical (1850-2000) gridded anthropogenic and biomass burning emissions of reactive gases and aerosols: methodology and application. Atmos Chem Phys 10(15):7017-7039

Lamarque JF, Kyle GP, Meinshausen M, Riahi K, Smith SJ, van Vuuren DP, Vitt F et al (2011) Global and regional evolution of shortlived radiatively-active gases and aerosols in the Representative Concentration Pathways. Clim Change 109(1-2):191

Lashof DA, Ahuja DR (1990) Relative contributions of greenhouse gas emissions to global warming. Nature 344(6266):529

Lehmann J, Coumou D, Frieler K (2015) Increased record-breaking precipitation events under global warming. Clim Change 132(4):501-515

L'Heureux ML, Mann ME, Cook BI, Gleason BE, Vose RS (2004) Atmospheric circulation influences on seasonal precipitation patterns in Alaska during the latter 20th century. J Geophys Res Atmos 109(D6)

Mauritsen T, Pincus R (2017) Committed warming inferred from observations. Nat Clim Change 7(9):652

Mitchell J, Wilson CA, Cunnington WM (1987) On $\mathrm{CO}_{2}$ climate sensitivity and model dependence of results. Q J R Meteorol Soc 113:293-322

Overland JE, Wang M (2007) Future climate of the North Pacific Ocean. Eos Trans Am Geophys Union 88(16):178 
Patz JA, Campbell-Lendrum D, Holloway T, Foley JA (2005) Impact of regional climate change on human health. Nature 438(7066):310

Renwick JA, Wallace JM (1996) Relationships between North Pacific wintertime blocking, El Niño, and the PNA pattern. Mon Weather Rev 124(9):2071-2076

Rodhe H (1990) A comparison of the contribution of various gases to the greenhouse effect. Science 248(4960):1217-1219

Rohde R, Muller R, Jacobsen R, Perlmutter S, Rosenfeld A, Wurtele J, Mosher S et al (2013) Berkeley earth temperature averaging process. Geoinf Geostat 1(2):1-13

Rowell DP, Jones RG (2006) Causes and uncertainty of future summer drying over Europe. Clim Dyn 27(2-3):281-299

Ruckstuhl C, Norris JR, Philipona R (2010) Is there evidence for an aerosol indirect effect during the recent aerosol optical depth decline in Europe? J Geophys Res Atmos 115(D4)

Ruckstuhl C, Philipona R, Behrens K, Collaud Coen M, Dürr B, Heimo A, Mätzler C, Nyeki S, Ohmura A, Vuilleumier L, Weller, M, Wehrli C, Zelenka A (2008) Aerosol and cloud effects on solar brightening and the recent rapid warming. Geophys Res Lett $35(12)$

Screen JA, Simmonds I (2010) The central role of diminishing sea ice in recent Arctic temperature amplification. Nature 464:1334-1337

Seager R, Cane M, Henderson N, Lee DE, Abernathey R, Zhang H (2019) Strengthening tropical Pacific zonal sea surface temperature gradient consistent with rising greenhouse gases. Nat Clim Change 9(7):517

Seidel DJ, Fu Q, Randel WJ, Reichler TJ (2008) Widening of the tropical belt in a changing climate. Nat Geosci 1(1):21

Seneviratne SI et al (2006) Land-atmosphere coupling and climate change in Europe. Nature 443.7108:205

Smith DM, Murphy JM (2007) An objective ocean temperature and salinity analysis using covariances from a global climate model. J Geophys Res Oceans 112(C2):1-19

Sutton RT, Dong B, Gregory JM (2007) Land/sea warming ratio in response to climate change: IPCC AR4 model results and comparison with observations. Geophys Res Lett 34(2)

Tian F, Dong B, Robson J, Sutton R (2018) Forced decadal changes in the East Asian summer monsoon: the roles of greenhouse gases and anthropogenic aerosols. Clim Dyn. https://doi.org/10.1007/ s00382-018-4105-7
Trenberth KE, Dai A, Van Der Schrier G, Jones PD, Barichivich J, Briffa KR, Sheffield J (2014) Global warming and changes in drought. Nat Clim Change 4(1): 17

Turnock ST et al (2016) The impact of European legislative and technology measures to reduce air pollutants on air quality, human health and climate. Environ Res Lett 11(2):024010

Turnock ST, Spracklen DV, Carslaw KS, Mann GW, Woodhouse MT, Forster PM, Sánchez-Lorenzo A et al (2015) Modelled and observed changes in aerosols and surface solar radiation over Europe between 1960 and 2009. Atmos Chem Phys 15(16):9477-9500

Twomey S (1977) The influence of pollution on the shortwave albedo of clouds. J Atmos Sci 34(7):1149-1152

Uematsu M, Duce RA, Prospero JM, Chen L, Merrill JT, McDonald RL (1983) Transport of mineral aerosol from Asia over the North Pacific Ocean. J Geophys Res Oceans 88(C9):5343-5352

Valcke S, Caubel A, Declat D, Terray L (2003) OASIS3 ocean atmosphere sea ice soil user's guide. Prisim project report, 2

Walsh JE, Chapman WL, Romanovsky V, Christensen JH, Stendel M (2008) Global climate model performance over Alaska and Greenland. J Clim 21(23):6156-6174

Walters DN, Best MJ, Bushell AC, Copsey D, Edwards JM, Falloon PD, Harris CM, Lock AP, Manners JC, Morcrette CJ, Roberts MJ, Stratton RA, Webster S, Wilkinson JM, Willett MR, Boutle IA, Earnshaw PD, Hill PG, MacLachlan C, Martin GM, MoufoumaOkia W, Palmer MD, Petch JC, Rooney GG, Scaife AA, Williams KD (2011) The Met Office Unified Model global atmosphere 30/31 and JULES global land 30/31 configurations. Geosci Model Dev 4(4):919

Whan K, Zscheischler J, Orth R, Shongwe M, Rahimi M, Asare EO, Seneviratne SI (2015) Impact of soil moisture on extreme maximum temperatures in Europe. Weather Clim Extremes 9:57-67

Publisher's Note Springer Nature remains neutral with regard to jurisdictional claims in published maps and institutional affiliations. 